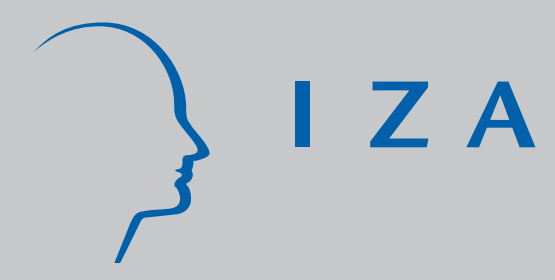

IZADP No. 1960

Employment Protection, Product Market Regulation and Firm Selection

Winfried Koeniger J ulien Prat

February 2006 


\title{
Employment Protection, Product Market Regulation and Firm Selection
}

\author{
Winfried Koeniger \\ IZA Bonn \\ and University of Bonn
}

Julien Prat

University of Vienna

and IZA Bonn

\section{Discussion Paper No. 1960 \\ February 2006}

\author{
IZA \\ P.O. Box 7240 \\ 53072 Bonn \\ Germany \\ Phone: +49-228-3894-0 \\ Fax: +49-228-3894-180 \\ Email: iza@iza.org
}

\begin{abstract}
Any opinions expressed here are those of the author(s) and not those of the institute. Research disseminated by IZA may include views on policy, but the institute itself takes no institutional policy positions.

The Institute for the Study of Labor (IZA) in Bonn is a local and virtual international research center and a place of communication between science, politics and business. IZA is an independent nonprofit company supported by Deutsche Post World Net. The center is associated with the University of Bonn and offers a stimulating research environment through its research networks, research support, and visitors and doctoral programs. IZA engages in (i) original and internationally competitive research in all fields of labor economics, (ii) development of policy concepts, and (iii) dissemination of research results and concepts to the interested public.
\end{abstract}

IZA Discussion Papers often represent preliminary work and are circulated to encourage discussion. Citation of such a paper should account for its provisional character. A revised version may be available directly from the author. 
IZA Discussion Paper No. 1960

February 2006

\section{ABSTRACT \\ Employment Protection, Product Market Regulation and Firm Selection*}

This paper analyzes the effect of labor and product market regulation in a dynamic stochastic equilibrium with search frictions. Modeling multiple-worker firms allows us to distinguish between the exit-and-entry (extensive) margin, and the hiring-and-firing (intensive) margin. We characterize analytically how both margins depend on regulation before we calibrate the model to the US economy. We find that firing costs matter most for the intensive margin. Fixed or set-up costs in the product market instead alter primarily the behavior of firms at the extensive margin. Moreover, we find important interactions between the policies through firm selection. Finally, the opposite effect of product and labor market regulation on job turnover rationalizes the empirically observed similarity of turnover rates across countries.

JEL Classification: $\quad \mathrm{E} 24, \mathrm{~J} 63, \mathrm{~J} 64, \mathrm{~J} 65$

Keywords: $\quad$ firing cost, product market regulation, firm selection, firm turnover, job turnover

Corresponding author:

Winfried Koeniger

IZA

P.O. Box 7240

53072 Bonn

Germany

Email: koeniger@iza.org

\footnotetext{
* We thank Pietro Garibaldi and participants of the IZA Prize Conference 2005 and workshop on 'Employment Protection and Labor Markets' for helpful comments.
} 


\section{Introduction}

Product and labor market regulations differ substantially across OECD countries. Whereas Anglo-Saxon countries have flexible labor markets and deregulated product markets, the opposite is the case for continental European countries. ${ }^{1}$ Although substantial differences remain, European product markets have undergone noticeable deregulation over recent years. Conversely, reforms in the labor market have been marginal and mostly limited to the introduction of more flexible contracts. ${ }^{2}$ This is why recent research has argued that interactions between labor and product market regulation might help to explain the different evolution of unemployment rates across European countries.

The coexistence of regulation in product and labor markets is a serious challenge for empirical researchers who are interested in the effects of labor market institutions on economic performance. Considering each type of regulation independently is misleading if there are important channels of interaction since then the effect of labor market institutions is confounded by changes in product market regulation. ${ }^{3}$ Thus, it is important to understand the qualitative and quantitative effects of both types of regulation in a unified theoretical framework wherein product and labor market regulation each play a distinctive role but also interact endogenously by changing the costs and benefits of the respective other policy.

In this paper we set up such a model, focussing on empirically important parts of regulation, such as wasteful firing $\operatorname{costs}^{4}$ in labor markets and administrative fixed and set-up costs in product markets. Usual matching models are not well suited to analyze these types of regulation since entry and exit are indistinguishable from job creation and job destruction

\footnotetext{
${ }^{1}$ The correlation coefficient between summary indicators for the stringency of employment protection legislation (EPL) and product market regulation (PMR) proposed in Nicoletti et al. (1999) is highly significant and equal to 0.72 .

${ }^{2}$ See Alesina et al. (2005), Figure 1, for the prevalence of product market deregulation from the 1970s to 1990s; and OECD (2004), chart 2.2, on the deregulation of EPL since the late 1980s.

${ }^{3} \mathrm{~A}$ recent illustration of this problem is in Lopez-Garcia (2003). Using data with country and time variations, she finds that the effect of EPL on unemployment falls dramatically in size and significance whenever start-up costs are included in the regressions.

${ }^{4}$ In reality, transfers between firms and workers are also an important component of employment protection legislation. For a recent discussion on the effects of severance payments see Garibaldi and Violante (2005).
} 
because of the "one-firm-one-worker" assumption. Instead we want to capture that barriers to entry limit the number of firms whereas firing costs influence firms' employment decision. Hence, we set up a model with multiple-worker firms which explicitly allows us to distinguish between the exit-and-entry (extensive) margin, and the hiring-and-firing (intensive) margin. We characterize analytically how both margins depend on the regulation policies before we calibrate the model to the US economy.

We find that firing costs primarily matter for adjustment at the intensive margin: incumbent firms that are exposed to exogenous changes in business conditions will hoard more or less labor depending on the adjustment costs. Fixed or set-up costs in the product market instead alter primarily the behavior of firms at the extensive entry margin and thus the total number of firms producing in equilibrium. The model also allows us to highlight important interactions. On the one hand, firing costs encourage exit for two reasons: firstly, they lower the asset value of the firm; secondly, they increase the incentive to declare bankruptcy since defaulting firms are exempted from firing costs. On the other hand, product market regulation matters for labor hoarding through a selection effect: higher fixed and set-up costs imply higher average firm productivity and larger average firm size. Job turnover per firm increases but since a smaller number of firms produces in equilibrium, the aggregate steady-state mobility costs decrease.

Furthermore, we find that the interaction between firing and set-up costs differs across firms. Incumbent firms favor higher barriers to entry as they benefit from the exclusion of less productive firms. The congestion externality in the labor market is mitigated and this partially compensates for the burden of higher firing costs. Nevertheless, for the welfare of the economy as a whole, low barriers to entry complement high firing costs. The intuition is that lower set-up costs foster firm creation and thus mitigate the higher incidence of firm destruction due to firing restrictions. As agents are risk neutral in our model, the insurance of workers by "larger" firms is not valued and the existence of a subset of high-turnover firms employing workers adds welfare.

Since heterogenous firms decide whether to enter in the good state and can exit if a bad shock occurs, our model generates predictions about the patterns of firm and job turnover in the steady state. In our numerical calibration we find that product and labor market 
regulation have quite different and potentially countervailing effects on firm and job turnover. Firing costs decrease job turnover but increase firm turnover because more firms exit in the bad state and default on firing costs. On the contrary, the selection effect of fixed and set-up costs intensifies job turnover per firm mostly because smaller search frictions decrease the recruitment costs.

These opposite effects on job turnover provide an alternative explanation to Bertola and Rogerson (1997) for why job turnover is similar across developed countries with different stringency of employment protection legislation (EPL). Whereas Bertola and Rogerson argue that rigid wages complement strict EPL in developed countries, we argue that the similar job-turnover rates can be explained by more product market regulation (PMR) in countries with stricter EPL.

Related literature. The interactions between product and labor market regulations have received much interest in recent years. Blanchard and Giavazzi (2003) focus on the bargaining power of workers as labor market regulation. They argue that higher rents in regulated product markets are complementary with more bargaining power in the labor market since workers try to appropriate some of the rents. Ebell and Haefke (2004) have extended the model to a dynamic context determining the type of bargain (individual or collective) as a function of product market regulation. In this paper, we take the type of bargain as exogenous and instead focus on employment protection legislation, a labor market policy which is very important in many OECD countries and at the same time quite heterogenous across them. Compared with the deterministic models mentioned above, we frame our analysis in a stochastic environment in order to analyze firing costs and turnover in a meaningful way.

We solve a dynamic stochastic equilibrium model with multiple-worker firms and frictions in the labor market. Imperfect labor markets with frictions imply realistic equilibrium unemployment and allow for a potentially positive welfare effect of market regulation. Although a dynamic model with multiple-worker firms and well-defined firm size is not easily solved, the distinction between administrative fixed and set-up costs per firm and firing costs per worker is most meaningful if multiple-worker firms have an intensive and extensive margin. ${ }^{5}$

\footnotetext{
${ }^{5}$ For an analysis of hiring subsidies and firing costs in one-worker firms see Mortensen and Pissarides
} 
Our paper builds on the model of Bertola and Caballero (1994), henceforth BC. We add an entry and exit decision to $\mathrm{BC}$ and maintain the assumption that workers are homogenous whereas firms are heterogenous. In our model firm heterogeneity also has a permanent component besides the standard stochastic component which fluctuates between two states, good and bad. Permanent productivity differences between firms allow us to determine two endogenous productivity thresholds: one above which firms decide to enter in the good state and another one below which firms exit in the bad state. ${ }^{6}$

As in BC, firm size is well defined because the production technology has decreasing returns to scale in labor and firms cannot hire immediately due to frictions in the labor market. Since wages are permanently renegotiated, this gives rise to intra-firm bargaining and overemployment. Firms exploit that an additional worker lowers the wage of all employed workers. This outcome of intra-firm bargaining has been derived in deterministic models such as the partial equilibrium analyses of Stole and Zwiebel (1996 a,b), the equilibrium analysis of Smith (1999) and, with multiple types of workers and capital, Cahuc et al. (2004).

The rest of the paper is structured as follows. In Section 2 we lay out the basic model. We define and calibrate the equilibrium to the US economy in Section 3. Section 4 provides a quantitative numerical analysis of the effect of regulation. The interactions between the two types of regulation are detailed in Section 5. We conclude in Section 6.

\section{Model}

In this section we set up the model and provide analytical results on the firms' behavior.

(2003) and Pissarides (2000), chapter 9. Since both policies affect the intensive hiring and firing margin in models with one-worker firms, they have a similar effect on the match surplus and hiring subsidies can be designed to offset the effects of firing costs.

${ }^{6}$ This relates to the analysis of Hopenhayn and Rogerson (1993) who analyze the effect of firing costs in a neoclassical model with job and firm turnover in the steady state. In their calibration firing costs have a substantial negative effect on average productivity, employment and consumption. 


\section{$2.1 \quad$ Set-up}

The economy is populated by a continuum of workers. Workers are assumed to be homogenous and infinitely-lived. They are employed by a continuum of firms whose mass $\mu$ is endogenously determined in equilibrium by the entry and exit conditions. Firms are indexed by the subscript $i$ so that $i \in[0, \mu]$. Contrary to workers, firms are heterogenous and differ with respect to their permanent total factor productivity $a_{i}$ and transitory differences in business conditions. Both firms and workers are risk neutral.

Technology. Each firm has access to a production technology that uses labor as the only input. The production technology has a fixed overhead component $f$ and a variable component. The variable component has decreasing returns to scale. The firm's labor-demand schedule is characterized using a linearization of the marginal revenues

$$
\rho_{i}^{g}=\eta_{i}^{g}-\sigma l_{i} \text { with } \eta_{i}^{g}=\eta\left(a_{i}, \varepsilon_{g}\right)
$$

and

$$
\rho_{i}^{b}=\eta_{i}^{b}-\sigma l_{i} \text { with } \eta_{i}^{b}=\eta\left(a_{i}, \varepsilon_{b}\right)
$$

where the superscript denotes whether the firm is in the good or bad transitory state. We assume that $\partial \eta / \partial a_{i}>0, \partial \eta / \partial \varepsilon_{j}>0$ with $\varepsilon_{g}>\varepsilon_{b}$. The permanent components $a_{i}$ are distributed according to an exogenous density over the interval $[0, \bar{a}]$. Hence their total mass is constant through time so that new $a_{i}$ cannot be created. In the remainder of the text, we will refer to $a_{i}$ as "production opportunities". In equilibrium, some production opportunities will be exploited by operating firms whereas others will be left unused. For concreteness, we assume that

$$
\eta_{i}^{b}=a_{i} \varepsilon_{b} \text { and } \eta_{i}^{g}=a_{i} \varepsilon_{g}
$$

The production technology implies that each firm has decreasing returns in employing workers. Thus, firm size is a well-defined concept and allows us to analyze the effect of firing costs and product market regulation for firms with multiple workers.

Institutions. Behavior in our economy is constrained by institutions in both the product and labor market. In the labor market, wasteful firing costs $F$ constrain firms' layoff deci- 
sions. In the product market, firms face a regulatory burden. They have to pay a wasteful flow cost $f$ in order to comply with regulation on licensing and other bureaucratic burden. We think of $f$ as capturing the administrative procedures and economic regulations that impede firms in each period in which they produce. In reality, barriers to entrepreneurial activity also account for a significant part of product market regulation (see Nicoletti et al. 1999). We model this constraint by assuming that firms face a cost of entry equal to $C$.

The labor market. The labor market is characterized by search frictions as in the standard Diamond-Mortensen-Pissarides model. We consider a Cobb-Douglas matching technology with constant returns so that every vacancy is matched to an unemployed worker at Poisson rate

$$
q\left(\theta_{t}\right)=\xi \theta_{t}^{\gamma},-1<\gamma<0
$$

where $\theta_{t} \equiv V_{t} / U_{t}, V_{t}$ denotes the stock of vacancies at time $t, U_{t}$ denotes the stock of unemployed workers and $\xi$ is the scaling factor of the matching function.

The hiring process consumes time and resources. As in BC, open vacancies $v_{i t}$ entail a flow cost $c v_{i t}^{2} / 2$ so that the marginal cost is $c v_{i t}$ and the number of posted vacancies is bounded.

\subsection{Firm behavior}

Our analysis focuses on the steady state so that time indices are dropped unless necessary. We first define the asset values of firms that always remain in the market and of firms that enter and exit. In the remainder of the paper we will refer to the former as "labor-hoarding firms" and to the latter as "non-permanent firms". Deriving these asset values is one of the main innovations of this paper compared with $\mathrm{BC}$ so that we analyze them in some detail. Then we use these asset values to determine firm selection.

Firms that exit the market declare bankruptcy, fire all workers and default on the firing costs. $^{7}$ We define the asset value of a firm $i$ in the bad and good state as $A_{i}^{b, n}$ and $A_{i}^{g, n}$,

\footnotetext{
${ }^{7}$ This assumption is similar to Belviso (2005). However, in our model with heterogenous firms, it is optimal that not all firms avoid firing costs by declaring bankruptcy but only "small" firms choose to default on firing costs if they are hit by a bad shock.
} 
where $n$ is a discrete variable which takes value 0 when firm $i$ declares bankruptcy in the bad state and 1 otherwise. We also apply superscripts 1 or 0 to the state and control variables. The asset value of a firm in the good state $A_{i}^{g, n}(\tau)$ depends on the time $\tau$ spent in this state. This is because hiring takes time. Introducing $\tau$ as a state variable enables us to keep track of the number of hired workers.

Asset values: labor-hoarding firms. Let us first characterize the asset values of a firm $i$ that does not declare bankruptcy if hit by a bad shock. The asset value in the bad state is defined as

$$
r A_{i}^{b, 1} \equiv r A^{1}\left(l_{i}^{1}(0) ; a_{i}, \varepsilon_{b}\right)=\pi_{i}^{b, 1}+v\left(A_{i}^{g, 1}(\tau=0)-A_{i}^{b, 1}\right),
$$

where $v$ is the Poisson hazard of receiving a good shock and

$$
\pi_{i}^{b, 1} \equiv \int_{0}^{l_{i}^{1}(0)}\left(\rho_{i}^{b}(l)-w_{i}^{b}\right) d l-f .
$$

The asset value is rather standard as it includes the profit flow $\pi_{i}^{b, 1}$ and the change of the asset value if a good shock arrives with Poisson rate $v$. The definition of the profit flow $\pi_{i}^{b, 1}$, however, differs compared with one-firm-one-worker models. Firms in the bad state pay wage $w_{i}^{b}$ to all workers and hoard labor $l_{i}^{1}(\tau=0)$. For the optimally chosen labor force $l_{i}^{1}(0)$, profits are defined as the integral of marginal revenues up to the employment level minus the wage bill $w_{i}^{b} l_{i}^{1}(0)$, minus the fixed operation cost $f .{ }^{8}$

Because hiring frictions make it impossible to adjust labor immediately to its optimal level, employment in the bad state equals employment of a firm that has just received a good shock and has spent $\tau=0$ time units in the good state. Firms post vacancies solely in the good state and the asset value of firm $i$ in the good state reads $r A_{i}^{g, 1}(\tau) \equiv r A^{1}\left(l_{i}^{1}(\tau), v_{i}^{1}(\tau) ; a_{i}, \varepsilon_{g}\right)=\pi_{i}^{g, 1}(\tau)+\delta\left(A_{i}^{b, 1}-A_{i}^{g, 1}(\tau)-F\left(l_{i}^{1}(\tau)-l_{i}^{1}(0)\right)\right)+\frac{d}{d \tau} A_{i}^{g, 1}(\tau)$,

\footnotetext{
${ }^{8}$ Note that firms take into account that more employment decreases wages, and thus overemploy workers (see the Appendix for results on wage determination). However, once the employment level is decided upon, each worker receives the same wage, so that the wage level is constant when we integrate over the marginal profit contribution of each worker. Note also that we set the constant of integration to zero without loss of generality.
} 
where $\delta$ is the Poisson hazard of receiving a bad shock and

$$
\pi_{i}^{g, 1}(\tau) \equiv \int_{0}^{l_{i}^{1}(\tau)}\left(\rho_{i}^{g}(l)-w_{i}^{g, 1}(\tau)\right) d l-\frac{c v_{i}^{1}(\tau)^{2}}{2}-f .
$$

The profit flows in the good state include the flow costs of vacancy posting $c v_{i}^{1}(\tau)^{2} / 2$. The asset value $A_{i}^{g, 1}(\tau)$ changes with $\tau$ as firms hire and converge to their maximum employment level $l_{i}^{1}(\tau \rightarrow \infty)$. The control variable of the firm is the number of posted vacancies so the envelope theorem implies that

$$
\frac{d}{d \tau} A^{g, 1}\left(l_{i}^{1}(\tau), v_{i}^{1}(\tau) ; a_{i}, \varepsilon_{g}\right)=\frac{\partial A^{1}\left(l_{i}^{1}(\tau), v_{i}^{1}(\tau) ; a_{i}, \varepsilon_{g}\right)}{\partial l_{i}^{1}(\tau)} l_{i}^{1}(\tau),
$$

where a dot denotes a derivative with respect to time $\tau$ spent in the good state. Inserting this expression for expected capital gains into the asset equation (1) allows us to rewrite it as a function of the optimal labor demand schedule

$$
r A_{i}^{g, 1}(\tau)=\pi_{i}^{g, 1}(\tau)+\delta\left(A_{i}^{b, 1}-A_{i}^{g, 1}(\tau)-F\left(l_{i}^{1}(\tau)-l_{i}^{1}(0)\right)\right)+\frac{\partial A^{1}\left(l_{i}^{1}(\tau), v_{i}^{1}(\tau) ; a_{i}, \varepsilon_{g}\right)}{\partial l_{i}^{1}(\tau)} q(\theta) v_{i}^{1}(\tau),
$$

where we substitute $i_{i}^{1}(\tau)=q(\theta) v_{i}^{1}(\tau)$ using the assumptions on the matching technology.

Asset values: non-permanent firms. We now characterize the asset values of a firm $i$ that declares bankruptcy if hit by a bad shock. We assume that the "ownership" of the production opportunity $a_{i}$ is lost after filing for bankruptcy. In other words, managers who declare bankruptcy do not retain the option to exploit the production opportunity when business conditions switch back to the good state. ${ }^{9}$ Managers operate in a perfectly competitive environment, so their outside option is equal to zero ${ }^{10}$

$$
A_{i}^{b, 0}=0
$$

\footnotetext{
${ }^{9}$ Alternatively, one could interpret $a_{i}$ as measuring managers' abilities. Then the production opportunities are retained after filing for bankruptcy. This interpretation has the interesting implication that entry costs deter firms from going bankrupt. However, calibrating the model shows that this effect is very small because of discounting. Since this assumption complicates the analysis, we find it more parsimonious and instructive to focus on the interpretation proposed in the main text.

${ }^{10}$ This holds if the supply of managers for profitable production opportunities is perfectly elastic. We view this as a first approximation and leave the task of explicitly endogenizing the market for managers to further research.
} 
Bankruptcy is an attractive option because: (i) it allows to save on wages and fixed costs in the bad state; (ii) bankrupt firms default on firing costs. Thus, the asset equation in the good state is given by

$$
r A_{i}^{g, 0}(\tau)=\pi_{i}^{g, 0}(\tau)+\delta\left(-A_{i}^{g, 0}(\tau)\right)+\frac{\partial A^{0}\left(l_{i}^{0}(\tau), v_{i}^{0}(\tau) ; a_{i}, \varepsilon_{g}\right)}{\partial l_{i}^{0}(\tau)} q(\theta) v_{i}^{0}(\tau)
$$

where 0 has been substituted for the asset value in the bad state.

\subsubsection{Extensive margin and firm selection.}

Exit rule. In steady-state some firms will decide to hoard labor while others will prefer to exit the market. The asset values derived in the previous section allow us to determine the permanent productivity threshold below which firms decide to exit the market. We solve the problem in a recursive way: the firm determines whether or not it will exit the market in the bad state, then it decides upon its optimal labor demand schedule. ${ }^{11}$

As the asset value $A^{b, 1}\left(a_{i}\right)$ is increasing in $a_{i}$ whereas the bankruptcy option $A^{b, 0}$ is independent of $a_{i}$, there exists a threshold productivity $a^{*}$ such that $A^{b, 1}\left(a_{i}\right) \lesseqgtr A^{b, 0}=0$ as $a_{i} \lesseqgtr a^{*}$. The firms with a permanent productivity below $a^{*}$ are always better off in the bad state by declaring bankruptcy. Using the asset equations above, we determine $a^{*}$ with the equation

$$
A^{b, 1}\left(a^{*}\right)=\frac{\pi^{b, 1}\left(a^{*}\right)+v A^{g, 1}\left(a^{*}, \tau=0\right)}{r+v}=0 .
$$

It remains to pin down $A_{i}^{g, 1}(\tau=0)$ for the marginal firm. Using $A^{b, 1}\left(a^{*}\right)=0$ and inserting the analytic expression for the profit flow, the asset value of the marginal firm in the good state can be rewritten as follows

$$
\begin{aligned}
(\delta+r) A^{g, 1}\left(a^{*}, \tau\right)= & \overbrace{\left(\eta^{g}\left(a^{*}\right)-\frac{\sigma}{2} l^{1}\left(a^{*}, \tau\right)-w^{g, 1}\left(a^{*}, \tau\right)\right) l^{1}\left(a^{*}, \tau\right)-f-\frac{c v^{1}\left(a^{*}, \tau\right)^{2}}{2}}^{\pi^{g, 1}\left(a^{*}, \tau\right)} \\
& -\delta F\left(l^{1}\left(a^{*}, \tau\right)-l^{1}\left(a^{*}, 0\right)\right)+\frac{\partial A_{i}^{g, 1}\left(l_{i}^{1}(\tau), v_{i}^{1}(\tau) ; a^{*}, \varepsilon_{g}\right)}{\partial l_{i}^{1}(\tau)} q(\theta) v^{1}\left(a^{*}, \tau\right) .
\end{aligned}
$$

\footnotetext{
${ }^{11}$ In order to rule out inconsistent choice, we notice that the exit decision is based on the value of the firm in the bad state so that firms necessarily choose the alternative which yields the highest asset value when $\varepsilon_{i}=\varepsilon_{b}$. In other terms, the firm's value in the good state may be higher if it could commit to hoard labor in the bad state, but it will never implement this production plan if it does better in the bad state by declaring bankruptcy.
} 
Optimal vacancy posting implies that

$$
\frac{\partial A_{i}^{g}\left(l_{i}^{1}(\tau), v_{i}^{1}(\tau) ; a^{*}, \varepsilon_{g}\right)}{\partial l_{i}^{1}(\tau)}=\frac{c v^{1}\left(a^{*}, \tau\right)}{q(\theta)} .
$$

As in $\mathrm{BC}$, the marginal value of employment is equal to the expected hiring costs. Inserting this expression in the previous asset equation, we obtain

$$
(\delta+r) A^{g, 1}\left(a^{*}, 0\right)=\left(\eta^{g}\left(a^{*}\right)-\frac{\sigma}{2} l^{1}\left(a^{*}, 0\right)-w^{g, 1}\left(a^{*}, 0\right)\right) l^{1}\left(a^{*}, 0\right)-f+\frac{c v^{1}\left(a^{*}, 0\right)^{2}}{2} .
$$

This equation enables us to evaluate the entry condition (2) to solve for $a^{*}$ using the optimal labor demand schedules derived below. Let us mention for future reference that firing costs $F$ decrease the asset values and thus increase the productivity of firms that produce in equilibrium through the entry and exit decision. However, their effect is less direct than that of fixed costs $f$, since firing costs do not enter explicitly in equation (3). Firing restrictions only matter through their effect on the vacancy-posting policy $v^{1}\left(a^{*}, 0\right)$ and hoarded labor $l^{1}\left(a^{*}, 0\right)$. This is due to the fact that the firm will have to pay firing costs solely in the distant future, when it will switch back from the good to the bad state.

Entry rule. We restrict our attention to the steady-state of the economy. In equilibrium, all the production opportunities above $a^{*}$ are exploited and remain filled independently of their idiosyncratic business conditions. Since the mass and distribution of production opportunities remain constant, the only vacant production opportunities are below $a^{*}$. Let $a^{* *}$ denote the lowest permanent productivity among firms which enter the market in the good state and exit in the bad state. The entry condition that determines $a^{* *}$ reads

$r A^{g, 0}\left(a^{* *}, 0\right)=\pi^{g, 0}\left(a^{* *}, 0\right)+\delta\left(-A^{g, 0}\left(a^{* *}, 0\right)\right)+\frac{\partial A^{g, 0}\left(l_{i}^{0}(0), v_{i}^{0}(0) ; a^{* *}, \varepsilon_{g}\right)}{\partial l_{i}^{0}(0)} q(\theta) v^{0}\left(a^{* *}, 0\right)=r C$, where $C$ is the entry cost. As before, optimality implies that the derivative of the asset value with respect to labor is equal to $c v^{0}\left(a^{* *}, 0\right) / q(\theta)$. Moreover, since $l^{0}\left(a^{* *}, 0\right)=0$, we have $\pi^{g, 0}\left(a^{* *}, 0\right)=-c \frac{v^{0}\left(a^{* *}, 0\right)^{2}}{2}-f$. Replacing these two expressions in the asset equation and simplifying yields

$$
A^{g, 0}\left(a^{* *}, 0\right)=\left(\frac{1}{r+\delta}\right)\left(\frac{c v^{0}\left(a^{* *}, 0\right)^{2}}{2}-f\right)=C .
$$


Since $v^{0}(a, 0)$ is increasing in $a$, the entry condition $A^{g, 0}\left(a^{* *}, 0\right)=C$ is equivalent to finding a permanent productivity $a^{* *}$ such that

$$
v^{0}\left(a^{* *}, 0\right)=\sqrt{\frac{2((r+\delta) C+f)}{c}} .
$$

Note again that product market regulation $(C, f)$ directly affects $a^{* *}$ whereas firing costs $F$ only matter by changing the vacancy posting of firms, that is the function $v^{0}(\cdot)$. Depending on the model's parameters (especially $C$ ), $a^{* *}$ might be larger than $a^{*}$. Then, there is no firm turnover. In most cases the equilibrium is characterized by the following cross-sectional distribution: the production opportunities below $a^{* *}$ are vacant, those between $a^{* *}$ and $a^{*}$ are exploited in the good state and left unused in the bad state, while production opportunities above $a^{*}$ remain filled by labor-hoarding firms.

\subsubsection{Intensive margin: hiring and firing.}

We briefly mention how firms adjust at the intensive margin. This section is quite similar to $\mathrm{BC}$ but for the fact that firms differ with respect to their permanent productivity shifter $a_{i}$ and that some firms do not hoard labor in the bad state.

Search frictions in the labor market imply that hiring takes time so that firms cannot immediately adjust their stock of employed workers upwards. Instead, firing of workers is immediate. The stock of employed workers at firm $i$ evolves according to

$$
l_{i, t+d t}^{n}=l_{i, t}^{n}+q\left(\theta_{t}\right) v_{i, t}^{n}+\Delta l_{i, t}^{n},
$$

where the firm $i$ sheds $\Delta l_{i t}$ workers if hit by a negative shock. Dropping time indexes, the shadow value of employment reads

$$
r S_{i}^{n}=\rho_{i}^{n}-\omega_{i}^{n}+\frac{d}{d \tau} S_{i}^{n}
$$

where $\omega_{i}^{n}\left(l^{n}\left(a_{i}, \tau\right), a_{i}\right)$ denotes the marginal cost of employment. Note that this marginal cost is not equal to the wage in our model since multiple-worker firms have monopsony power and take into account the effect of their marginal employment decision on the wages of all workers. 
Labor demand schedule of "non-permanent" firms. The shadow value of an additional worker in the bad state depends on whether or not the firm declares bankruptcy. If $a_{i}<a^{*}$, so that a firm exits the market when hit by a bad shock, the shadow value is obviously equal to zero

$$
S_{i}^{b, 0}=0
$$

In the good state the firms decide to hire so that the shadow value equals the expected hiring cost

$$
S_{i}^{g, 0}(\tau)=\frac{c v_{i}^{0}(\tau)}{q(\theta)}
$$

Using the linearization of the revenue function, we find that

$$
\eta_{i}^{g, 0}-\sigma l_{i}^{0}(\tau)-\omega_{i}^{g, 0}(\tau)+\delta\left(-\frac{c v_{i}^{0}(\tau)}{q(\theta)}\right)+\frac{d}{d \tau} \frac{c v_{i}^{0}(\tau)}{q(\theta)}=r \frac{c v_{i}^{0}(\tau)}{q(\theta)} .
$$

Given that bankrupt firms default on firing costs, their optimal labor demand schedule is independent of $F$. This means that the entry rule (4) is not directly affected by the stringency of EPL. There will be an equilibrium effect, however, as we will see in the numerical solution below.

Labor demand schedule of "labor-hoarding" firms. If $a_{i} \geq a^{*}$, firm $i$ decides to both fire and hoard labor when hit by a bad shock. Then, the shadow value of an additional worker must be equal to the firing cost

$$
S_{i}^{b, 1}=-F
$$

The shadow value in the good state is determined as before, so that

$$
S_{i}^{g, 1}(\tau)=\frac{c v_{i}^{1}(\tau)}{q(\theta)}
$$

Since firing is instantaneous, each firm that fires has the same employment level conditional on permanent productivity $a_{i}$. The employment of firms in the good state depends on how long firms have been in the good state. Using the linearization of the revenue function and the firing condition, we find that firing in the bad state is determined by

$$
\eta_{i}^{b, 1}-\sigma l_{i}^{1}(0)-\omega_{i}^{b, 1}(0)+v\left(\frac{c v_{i}^{1}(0)}{q(\theta)}-(-F)\right)=-r F
$$


and hiring in the good state at time $\tau$ is given by

$$
\eta_{i}^{g, 1}-\sigma l_{i}^{1}(\tau)-\omega_{i}^{g, 1}(\tau)+\delta\left(-F-\frac{c v_{i}^{1}(\tau)}{q(\theta)}\right)+\frac{d}{d \tau} \frac{c v_{i}^{1}(\tau)}{q(\theta)}=r \frac{c v_{i}^{1}(\tau)}{q(\theta)}
$$

Contrary to the conditions for the extensive margin (2), (3) and (4) the conditions for the intensive margin (8) and (9) explicitly depend on firing costs $F$ whereas fixed costs $f$ or set-up costs $C$ only have an implicit effect. Although higher fixed or set-up costs do not affect the optimal labor demand schedule of a given firm directly, they modify the distribution of operating firms through the selection effect at the extensive margin. As only more productive firms enter a more regulated market and the hiring and firing condition depend on $a_{i}$, fixed and set-up costs matter for aggregate labor hoarding. The selection effect also induces an equilibrium effect by feeding back into the optimal recruitment policy, and thus changes the aggregate unemployment rate and labor market tightness. We will illustrate this interaction further when we solve the model numerically in the next section.

The asset value of the worker, wages and the equilibrium are solved for quite similarly to $\mathrm{BC}$ so that we refer for these derivations to the Appendix. The model can be solved largely analytically but for the two conditions that determine hoarded labor, $l_{i}^{1}(0)$, and vacancies initially posted in the good state, $v_{i}^{n}(0) .{ }^{12}$ Compared with $\mathrm{BC}$ the permanent productivity shifter $a_{i}$ implies that the two conditions also depend on the average number of vacancies posted. ${ }^{13}$

\footnotetext{
${ }^{12}$ For the social-planner's problem one can show in closed form what we find numerically for the decentralized equilibrium (in which wage determination complicates the analysis). For a given $a_{i}$, firms that exit in the bad state post more vacancies in the good state because these firms do not have to pay the firing costs and do not hoard labor in the bad state. These results are available on request.

${ }^{13}$ This is because the wage of the employed worker in the bad state, $w_{i}^{b}$, depends on the outside option of unemployment which is a function of the average vacancies posted across firms in the good state. The posted vacancies in each firm summarize expected future employment changes in these firms which are important for expected future wages because of decreasing returns, intrafirm bargaining and the monopsony power of firms. See the Appendix for further details.
} 


\section{Equilibrium}

In this section we define the equilibrium, describe the numerical algorithm and calibrate our model to the US economy. Then we discuss the robustness of the calibration to some changes of important parameters.

Equilibrium definition. We define a search equilibrium for the economy as a set of aggregate quantities $\{L, V\}$, matching rate $q(\theta)$, permanent productivity thresholds $\left\{a^{* *}, a^{*}\right\}$, employment distribution $\mu\left(l \mid a_{i}\right)$ and infinite sequences for quantities $\left\{l_{i}^{n}(\tau), v_{i}^{n}(\tau)\right\}_{\tau=0}^{\infty}$ and prices $\left\{w_{i}^{b}, w_{i}^{g, n}(\tau)\right\}_{\tau=0}^{\infty}$ such that:

- Given the matching rate and prices, $\left\{l_{i}^{n}(\tau), v_{i}^{n}(\tau)\right\}_{\tau=0}^{\infty}$ solve firm $i$ 's optimization problem.

- Wages $\left\{w_{i}^{b}, w_{i}^{g, n}(\tau)\right\}_{\tau=0}^{\infty}$ are the solution of the Nash-bargaining problem.

- Permanent productivity thresholds $\left\{a^{* *}, a^{*}\right\}$ are determined by the optimal entry and exit decisions of firms.

- Aggregate quantities $\{L, V\}$ result from the aggregation of firms' optimal labor demand schedules.

- The matching rate $q(\theta)$ is given by the aggregate matching function.

- The flows into and out of the employment distribution $\mu\left(l \mid a_{i}\right)$ balance out.

The derivation of the equilibrium can be found in the Appendix.

Cross-sectional efficiency. As already mentioned by BC, solving the social planner's problem makes clear that the decentralized equilibrium is not efficient because of the standard congestion externality. Because of intra-firm bargaining distortions and firm heterogeneity, the standard Hosios condition is not enough to restore efficiency. For the purposes of this paper, however, it is important to note that the congestion externalities are rather unimportant for the parameter values of the calibrated model described below. ${ }^{14}$

\footnotetext{
${ }^{14}$ The vacancy cost $c=0.01$, required to match realistic unemployment rates and duration, implies that aggregate vacancy posting costs are very small.
} 
The numerical algorithm. The algorithm proceeds in three steps. In Step 1, we set starting values for the average number of vacancies, labor market tightness $\theta$ and the productivity $a^{*}$ of the marginal firm. In Step 2, we solve for $v^{1}\left(a^{*}, 0\right), l^{1}\left(a^{*}, 0\right)$ and use the solution for $v^{0}\left(a^{* *}, 0\right)$ to determine $a^{* *}$. We then update the average number of vacancies and $\theta$. As long as these two values have not converged up to numerical precision of $10^{-6}$, we repeat Step 2. Otherwise we continue with Step 3 and update $a^{*}$ using the steady-state condition $A^{b, 1}\left(a^{*}\right)=0$. Unless $a^{*}$ has converged up to numerical precision of $10^{-6}$, we update $\theta$ and the average number of vacancies, and restart the algorithm at Step 2. Our numerical results indicate that the equilibrium labor market tightness $\theta$ is locally unique. ${ }^{15}$

Calibration. For our computations we assume that production opportunities are uniformly distributed so that $a_{i} \sim U(0, \bar{a})$. The constant density facilitates the interpretation of the numerical results. The upper bound of the uniform distribution can be tied down using the normalization to 1 of total labor in the frictionless economy. ${ }^{16}$

We set the annual interest rate $r$ to 0.05 . The utility flow in unemployment $b=0.05$, which is $43 \%$ of the average wage in the flexible economy as we will see below. This value is within the range of commonly assumed values. We check that the value $b$ implies that workers in the frictionless economy find it optimal to supply labor in the good state so that $b \leq \eta_{i}^{g}-\sigma l_{i}$, for all $a_{i}$. Indeed, we find that for $\sigma=0.4$ and $\varepsilon_{g}=1$ this condition is always

\footnotetext{
${ }^{15}$ We calculate the slope of the feedback locus $\theta^{\prime}(\theta)$ when we compute $\theta$ (in each iteration for each given value of $a^{*}$. In the program we check that the locus $\theta^{\prime}(\theta)$ intersects only once with the 45 -degree line. We have always found a unique equilibrium for positive $\theta$ given the parameter values we considered.

${ }^{16}$ We restrict our attention to the case where firms in the frictionless economy operate solely in the good state. All labor is shed if a bad shock occurs. Since the workforce in the good state is equal to $l(a)=\frac{a \varepsilon_{g}-b}{\sigma}$, the normalization of employment to full employment in the frictionless economy yields
}

$$
1=\frac{v}{v+\delta} \frac{1}{\bar{a}-\underline{a}} \int_{b}^{\bar{a}} l(a) d a=\left(\frac{v}{v+\delta}\right)\left(\frac{1}{\bar{a}-\underline{a}}\right)\left(\frac{1}{2 \sigma} \varepsilon_{g}\left(\bar{a}^{2}-b^{2}\right)-\frac{b}{\sigma}(\bar{a}-b)\right) .
$$

Setting $\underline{a}=0$ implies that $\bar{a}$ is the positive root of a quadratic equation

$$
\bar{a}=\frac{\frac{v+\delta}{v}+\frac{b}{\sigma}+\sqrt{\left(\frac{v+\delta}{v}+\frac{b}{\sigma}\right)^{2}+\left(\frac{b^{2} \varepsilon_{g}\left(\varepsilon_{g}-2\right)}{\sigma^{2}}\right)}}{\varepsilon_{g} / \sigma} .
$$


satisfied in equilibrium. We set $\varepsilon_{b}$ equal to $b / \bar{a}$. This value implies that in the bad state there is no wage for which firms employ a positive amount of labor in the frictionless economy.

The dynamic transitions between good and bad states are parametrized as $\delta=0.5$ and $v=1$. This implies that a created job has a $60 \%$ chance to persist for one year or more whereas the chance for a destroyed job is $40 \%$. The former is consistent with estimates reported in Davis et al. (1996) whereas $v$ is higher than suggested by their evidence. A higher $v$ makes it more attractive for firms to hoard labor also at low levels of unemployment. We need this for technical reasons as further explained below. We assume a matching efficiency $\gamma=-0.5$ which is in line with parameters commonly used in the literature (see Petrongolo and Pissarides, 2000). In order to be able to match empirically plausible unemployment rates, we set the bargaining power of workers to $\beta=0.2$ which is slightly smaller than the estimates reported in Flinn (2005). Below we check the robustness of our results for a bargaining power of $\beta=0.3 .{ }^{17}$ Finally, we assume that the flow cost of an additional vacancy is $c=0.01$ and the scaling factor of the matching function $\xi=2.5$. Both parameters are set to match a reasonable unemployment rate, labor market tightness and thus unemployment duration. The value of $c$ equals $1 / 12$ of the average wage, which yields an average recruiting cost close to one month's wage (see Hamermesh, 1993). As we will discuss further below, the small value of $c$ is crucial for the model to predict realistic unemployment duration. The scaling factor instead allows for realistic unemployment rates.

In the calibration of our model there is a tension between targeting low unemployment rates and unemployment duration together with all firms with $a_{i} \geq a^{*}$ hoarding labor. The latter is important because it simplifies the solution of the model since the shadow value of labor in the bad state is then determined by (8). However, we need small search frictions in the labor market which imply realistic values for the level and duration of unemployment but also less labor hoarding. In order to generate some labor hoarding for all firms with $a_{i} \geq a^{*}$, we calibrate fixed and firing costs in the flexible economy as $f=0.1$ and $F=0.04$. This is not unrealistic compared with an average wage of 0.12 since even in relatively flexible

\footnotetext{
${ }^{17}$ Note that efficiency could not be restored in this model if we set $\beta=-\gamma$, as the Hosios condition might suggest. As pointed out in BC, cross-sectional efficiency is more difficult to achieve because of the additional intra-firm bargaining distortions and heterogenous vacancy posting of firms. This holds a fortiori in this model with permanent productivity differences $a_{i}$.
} 


\begin{tabular}{|c|c|c|c|c|c|c|c|c|c|}
\hline \multicolumn{10}{|c|}{ Parameters Values } \\
\hline$\sigma$ & $r$ & $\delta$ & $v$ & $\xi$ & $\beta$ & $b$ & $c$ & $F$ & $C$ \\
\hline 0.4 & 0.05 & 0.5 & 10.5 & 2.5 & 0.2 & 0.05 & 0.01 & $0.04 \quad 0.1$ & 0.1 \\
\hline \multicolumn{10}{|c|}{ Equilibrium Variables } \\
\hline \multicolumn{6}{|c|}{ Unemployment rate $U$ (in \%) } & \multicolumn{4}{|c|}{7.622} \\
\hline \multicolumn{6}{|c|}{ Vacancies $V$} & \multicolumn{4}{|c|}{0.341} \\
\hline \multicolumn{6}{|c|}{ Labor mkt. tightness $\theta$} & \multicolumn{4}{|c|}{4.472} \\
\hline \multicolumn{6}{|c|}{ Output $Y$} & \multicolumn{4}{|c|}{0.388} \\
\hline \multicolumn{6}{|c|}{ Welfare $\Omega$} & \multicolumn{4}{|c|}{0.329} \\
\hline \multicolumn{6}{|c|}{ Productivity $a_{i}$ (average) } & \multicolumn{4}{|c|}{0.895} \\
\hline \multicolumn{6}{|c|}{ Prod. margins $\left(a^{* *}, a^{*}\right)$} & \multicolumn{4}{|c|}{$(0.486,0.506)$} \\
\hline \multicolumn{6}{|c|}{ Average firm size } & \multicolumn{4}{|c|}{1.489} \\
\hline \multicolumn{6}{|c|}{ Av. labor hoarded } & \multicolumn{4}{|c|}{0.193} \\
\hline \multicolumn{6}{|c|}{ Average wage } & \multicolumn{4}{|c|}{0.115} \\
\hline
\end{tabular}

Table 1: Equilibrium values in the flexible "US" economy.

economies such as the US, firms face some administrative costs to maintain operations and lay off workers if these lay-offs are considered "unfair" (see OECD, Ch. 2, 1999; Autor, Donohue and Schwab, 2006). Our calibration implies that the firm with $a_{i}=a^{*}$ just hoards a tiny amount of labor $l_{i}(0)$ in the bad state. We calibrate set-up costs $C=0.1$ so that the hazard rate of bankruptcy is equal to $0.8 \%$ per year, which is realistic for publicly traded firms in the US economy (see www.bankruptcydata.com).

Table 1 displays the equilibrium for the flexible economy with $f=C=0.1$ and $F=0.04$ which we call the "US". The calibration matches the level and duration of unemployment in the flexible "US" economy quite well (see, for example, Abrahams and Shimer, 2002): the average unemployment duration is 2.3 month and an unemployment rate of $7.6 \%$ is realistic for the US in the last decades. Production opportunities $a_{i}<a^{* *}=0.49$ are vacant. Firms with $a_{i} \in[0.49 ; 0.51]$ declare bankruptcy if hit by a bad shock. Independently of their idiosyncratic business conditions, all production opportunities between $a^{*}=0.51$ and 
$\bar{a}=1.3$ are exploited. ${ }^{18}$

For the assumed uniform distribution, the average firm size reported in Table 1 can be computed as total employment over the mass of producing firms. This measure equals 1 if there is full employment and all production opportunities are exploited. In our calibration the average size is 1.49 which results because of deviations on the intensive and extensive margin from this benchmark. The amount of average labor hoarded is 0.19 , that is $1 / 7$ of the average firm size. Finally, the output measure in Table 1 is defined net of steady-state mobility and vacancy costs. We then subtract fixed costs of all producing firms and take into account the utility flow of the unemployed for our measure of welfare (see the Appendix for the analytic expressions).

Robustness. Before analyzing changes in the policy parameters $(f, C, F)$, let us mention how the equilibrium depends on some important parameter values. ${ }^{19}$ For brevity we only summarize the main insights. A higher utility during unemployment $b=0.06$ or a bargaining power of workers $\beta=0.3$ both increase unemployment and unemployment duration. However, $\beta$ has a stronger selection effect than $b$ : less firms operate in equilibrium and average productivity increases. Decreasing $\sigma$, and so reducing the elasticity of the firms' marginal revenue with respect to employment, augments the number of posted vacancies, the average firm size and the amount of labor hoarded. As a result, the unemployment rate and duration fall substantially. ${ }^{20}$ A slightly smaller flow cost of vacancy posting $c=0.0095$ also substantially lowers the unemployment rate and duration. The lower cost of posting vacancies favors firms with a high permanent productivity $a_{i}$ since they tend to post more vacancies. Thus more production opportunities are vacant, i.e., $a^{* *}$ and $a^{*}$ increase slightly. Firms have a larger average size and hoard less labor in the bad state since hiring is less costly. Both a

\footnotetext{
${ }^{18}$ Our model produces a left-skewed cross-sectional distribution for wages and a U-shaped distribution of employment over firms with different size which are roughly consistent with empirical data. Our model also generates a positive firm-size wage premium and smaller wage dispersion in larger firms as in Bertola and Garibaldi (2001). Results on the cross-sectional distribution are available on request.

${ }^{19}$ We keep constant the other parameters which depend on $\sigma$ or $b$ (e.g. $\bar{a}$ ). More detailed numerical results are available on request.

${ }^{20}$ This is similar to Smith (1999) who showed that more overemployment resulting from concave production exacerbates the congestion externality and thus reduces entry and aggregate employment.
} 
smaller $c$ or $\sigma$ imply that regulation has a smaller effect on the unemployment rate.

Many papers have argued that the volatility of the economic environment is substantially higher today than it used to be in the 1960 and 1970s (see Ljungqvist and Sargent, 1998, and their references). Whereas Ljungqvist and Sargent argue that the size of the shock has increased, we augment the frequency of the turbulence by setting $\delta=0.7$ and $v=1.4$ so that created jobs have $50 \%$ chance to persist more than a year whereas destroyed jobs only persist more than a year with $25 \%$ probability. These parameter changes leave the steadystate probability mass in the bad state unchanged at $\delta /(\delta+v)=1 / 3$, but decrease the persistence of each state.

Not surprisingly, turbulence increases frictional unemployment. Nevertheless, the unemployment duration decreases because more vacancies are posted. Higher steady-state mobility costs reduce output and welfare. More interestingly, higher turbulence implies that $a^{* *}$ and $a^{*}$ increase, so that only firms with higher permanent productivity continue to produce. Since firms that only operate in the good state produce for a shorter expected duration, $a^{* *}$ increases more than $a^{*}$ and the incidence of bankruptcy decreases. Average firm size is slightly lower as firms in the good state converge to smaller employment levels $l_{i}(\tau \rightarrow \infty)$. Finally, more labor is hoarded in the bad state so that wages are lower on average. The effect of turbulence on labor hoarding is very intuitive: if a bad shock is less persistent, firms will find it less attractive to lay off workers even if firing costs are low. Firms hoard labor to avoid labor market frictions whereas firing costs are much less relevant for labor hoarding in an economy with high turbulence: the implied elasticity of labor hoarding with respect to firing costs falls.

In the following sections we analyze the effect of regulation on the equilibrium. We start by presenting results on the effect of fixed, entry and firing costs in Section 4 before we characterize the interactions between regulations in Section 5 .

\section{The effect of regulation}

The selection effect of fixed costs. As can be seen from equations $(A 13),(A 14)$ and $(A 15)$ in the Appendix, the fixed costs $f$ do not directly enter in the optimal labor demand 


\begin{tabular}{|c|c|c|c|c|}
\hline & $U S$ & & & \\
\hline \multirow[t]{2}{*}{$F=0.04$} & $f=0.1$ & $f=0.15$ & $f=0.1$ & $f=0.15$ \\
\hline & $C=0.1$ & $C=0.1$ & $C=0.15$ & $C=0.15$ \\
\hline Equilibrium Variables & $(1)$ & $(2)$ & $(3)$ & $(4)$ \\
\hline Unempl. rate $U$ (in \%) & 7.622 & 8.413 & 7.873 & 8.900 \\
\hline Vacancies $V$ & 0.341 & 0.305 & 0.328 & 0.285 \\
\hline Labor mkt. tightness $\theta$ & 4.472 & 3.625 & 4.162 & 3.120 \\
\hline Output $Y$ & 0.388 & 0.384 & 0.386 & 0.381 \\
\hline Welfare $\Omega$ & 0.329 & 0.300 & 0.329 & 0.299 \\
\hline Productivity $a_{i}$ (average) & 0.895 & 0.923 & 0.900 & 0.929 \\
\hline Prod. margins $\left(a^{* *}, a^{*}\right)$ & $(0.486,0.506)$ & $(0.531,0.579)$ & $(0.514,0.502)$ & $(0.553,0.573)$ \\
\hline Average firm size & 1.489 & 1.584 & 1.503 & 1.602 \\
\hline Av. labor hoarded & 0.193 & 0.208 & 0.193 & 0.206 \\
\hline Average wage & 0.115 & 0.106 & 0.112 & 0.101 \\
\hline
\end{tabular}

Table 2: Equilibrium values for different fixed costs and set-up costs.

schedules. Since vacancy posting and labor hoarding decisions are based on workers' marginal revenues, it is clear that fixed costs do not influence the decisions of firms at the intensive margin.

Fixed costs, however, reduce firms' asset values. As the least profitable firm just breaks even, it is driven out of business by a tightening of administrative regulation. In terms of the model's parameters this means that $a^{* *}$ and $a^{*}$ increase, as can be seen by comparing columns (1) and (2) or (3) and (4) in Table 2, where we increase fixed costs from 0.1 to 0.15 (for different levels of set-up $\operatorname{cost} C$ ). Furthermore, the impact on $a^{*}$ is stronger so that fixed costs increase the size of the interval $\left[a^{* *} ; a^{*}\right]$ in which firms declare bankruptcy. Given that non-permanent firms do not pay the fixed costs in the bad state, their asset values fall relatively less than the asset values of the labor hoarding firms. Quantitatively, for low set-up costs $C=0.1$, higher fixed costs imply that the incidence of bankruptcy increases from $0.8 \%$ to $2 \%$. 
This selection effect on $a^{* *}$ and $a^{*}$ decreases labor market tightness and thus reduces wages by lowering the outside option of workers. The operating firms take advantage of their stronger bargaining position through an increase in both hoarded labor and targeted employment in the good state $l_{i}(\tau \rightarrow \infty)$. The new equilibrium is characterized by a smaller number of larger firms. Notice that labor hoarding remains nearly constant so that most of the adjustment is achieved through an increase of the firms' sizes in the good state. This implies that firms destroy on average more jobs when they are hit by a bad shock. This positive turnover effect on labor hoarding firms is reinforced by the fact that a larger share of firms declares bankruptcy and sheds all workers. Although the effect on firm size compensates the selection effect to a certain extent, the latter prevails so that labor market tightness decreases and unemployment increases substantially.

The selection effect of barriers to entry. Table 2 also displays the equilibrium outcomes for higher set-up costs $C=0.15$, again for different levels of fixed costs. Not surprisingly, higher barriers to entry decrease the number of operating firms and slightly increase average productivity and average firms' size. The increase in unemployment and unemployment duration leads to a decline in wages. Set-up costs also decrease welfare and output. These negative effects are quantitatively smaller than for fixed costs because the set-up costs do not directly affect the asset value of the firm once it has entered the market. ${ }^{21}$

More interestingly, barriers to entry have opposite effects on the exit and entry margins: they lower $a^{*}$ and raise $a^{* *}$, so that less firms declare bankruptcy in the bad state. On the one hand, more production opportunities are exploited in the bad state because the barriers to entry isolate operating firms from the competition of potential entrants. As set-up costs do not affect their revenues, the labor hoarding firms actually benefit from an increase in $C$. On the other hand, less firms are created due to the higher cost of entry. This effect on $a^{* *}$ is more sizeable and positive as can be seen analytically from the entry rule (4). Column (3) shows that set-up costs can deter entry to such an extent that $a^{* *}>a^{*}$. In other terms, for sufficiently high set-up costs, the equilibrium may exhibit no bankruptcy and no firm turnover.

\footnotetext{
${ }^{21}$ The negative welfare effect remains if fixed and/or set-up costs are rebated at the aggregate level.
} 


\begin{tabular}{lllll}
\hline \hline & $U S$ & Partial & Equilibrium & Full effect \\
\hline fixed cost $f=0.1$ & & $\left(\right.$ given $\left.\theta, a^{*}, a^{* *}\right)$ & $\left(\right.$ given $\left.a^{*}, a^{* *}\right)$ & \\
set-up cost $C=0.1$ & $F=0.04$ & $F=0.09$ & $F=0.09$ & $F=0.09$ \\
\hline Equilibrium Variables & $\mathbf{( 1 )}$ & $\mathbf{( 2 )}$ & $\mathbf{( 3 )}$ & $\mathbf{( 4 )}$ \\
\hline Average labor hoarded & 0.193 & 0.325 & 0.313 & 0.317 \\
Average firm size & 1.489 & 1.509 & 1.499 & 1.507 \\
Unempl. rate $U$ (in \%) & 7.622 & 6.400 & 6.995 & 6.953 \\
Labor market tightness $\theta$ & 4.472 & 4.875 & 4.462 & 4.552 \\
Prod. margins $\left(a^{* *}, a^{*}\right)$ & $(0.486,0.506)$ & $(0.486,0.506)$ & $(0.486,0.506)$ & $(0.482,0.525)$ \\
\hline \hline
\end{tabular}

Table 3: Decomposition of the effect of firing costs.

The interactions between fixed costs and entry costs. Comparing the unemployment rates reported in Table 2 shows that the two regulations interact negatively since their joint increase (see column (4)) leads to bigger job losses than the sum of their independent increases (see columns (2) and (3)). Intuitively, the selection effect is reinforced as the two regulations increase the costs and reduce the profits of exploiting vacant production opportunities.

The effect of EPL. The mechanism through which EPL affects the equilibrium is more intricate because firing costs also directly modify the labor demand schedules of firms. As explained in Bentolila and Bertola (1990), the partial equilibrium effect of firing costs yields less labor mobility and more labor hoarding. Firms respond to the change in labor market tightness by adjusting the number of posted vacancies. This equilibrium effect dampens the imbalance between the partial equilibrium effects on the hiring and firing margins. To the extent that the labor hoarding adjustments prevail, firing costs and employment are positively related in equilibrium.

Both partial equilibrium and equilibrium effects were already at work in BC. Since our model has an extensive adjustment margin, firing costs also have an additional selection effect. Table 3 decomposes the effect of firing costs into: (i) the partial equilibrium effect (for given $a^{* *}, a^{*}$ and $\theta$ ), (ii) the equilibrium effect through changes in $\theta$ for given $a^{* *}$ and 
$a^{*}$, (iii) the selection effect on $a^{* *}$ and $a^{*}$. The table analyzes the effect of increasing firing cost $F$ from 0.04 to 0.09 for fixed and set-up cost $f=C=0.1$.

Column (2) displays the partial equilibrium effect of higher firing cost. As expected, employment protection stimulates labor hoarding and the average firm's size increases. Hence, positive labor adjustments at the firing margin prevail over negative adjustments at the hiring margin. This is why the partial equilibrium effect on employment is positive. The fourth row displays the new labor market tightness. As the number of unemployed and posted vacancies decrease, the labor market becomes tighter. Obviously, the value of $\theta$ reported in column (2) is not an equilibrium outcome since we assume that firms make their choice based on the value of $\theta$ in column (1). The equilibrium adjustments resulting from the discrepancy between the two values of $\theta$ are reported in column (3). As explained before, a higher labor market tightness induces firms to lower their labor demand, so that both labor hoarding and vacancy posting decrease. The equilibrium effect of firing costs on unemployment is positive and the equilibrium labor market tightness is substantially lower.

Of most interest to our analysis are the differences between columns (3) and (4) since they capture the selection effect that is new in our model. Although the selection effect of fixed and firing costs on $a^{*}$ are qualitatively alike, their magnitude substantially differs. ${ }^{22}$ Given that the decision to remain in the market is based on the asset value of the firm in the bad state, firing costs are heavily discounted since they will have to be paid in the remote future. Instead, fixed costs burden the profit of the firm at each instant so that they have a more noticeable influence on the extensive margin.

Conversely, the selection effect of fixed and firing costs on $a^{* *}$ are different in both quantitative and qualitative terms. Whereas fixed costs substantially increase $a^{* *}$, the impact of firing costs is negative and quantitatively small. The reason is that "non-permanent" firms are exempted from EPL. Hence, firing costs do not affect directly their asset values $A_{i}^{g, 0}(0)$. Instead, "labor hoarding" firms $\left(a_{i}>a^{*}\right)$ are hurt by firing restrictions and thus post less vacancies in the good state. Ceteris paribus, the "non-permanent" firms $\left(a_{i} \in\left[a^{* *} ; a^{*}\right]\right)$ benefit from the increase in the rate of vacancy filling. This externality augments the incentives to enter the labor market in the good state so that $a^{* *}$ falls. ${ }^{23}$

\footnotetext{
${ }^{22}$ Compare the values of $a^{*}$ in columns (4) of Table 3 with its counterpart in column (2) of Table 2.

${ }^{23}$ Note that the analytical solution for $A^{g, 0}\left(a^{* *}, 0\right)$ does not depend on firing costs so that firing costs only
} 
Turning our attention to employment, we notice that the selection effect is positive. The sign of the relationship is due to the decrease in $a^{* *}$ and so crucially hinges on the assumption that firms can declare bankruptcy. On the contrary, when the model does not allow firms to declare bankruptcy, the selection effect unambiguously raises unemployment. Thus, the sign and size of the selection effect on unemployment depends importantly on whether small firms (with low permanent productivity $a_{i}$ ) can "avoid" firing costs using the bankruptcy option. This motivates why, in countries with strict EPL like Italy or Germany, this legislation does not apply to small firms with employment below a certain threshold. ${ }^{24}$

Finally, it is worth emphasizing that the sign of the relationship between EPL and unemployment is ambiguous. Depending on the parameter values, it can be either positive or negative. Nevertheless, doing comparative statics around the proposed equilibrium we have found that the effects are locally robust.

\section{Interaction of labor and product market regulation}

We now investigate the interactions between labor and product market regulation. We first compare the welfare in steady states with different labor and product market regulation. Although steady-state comparisons neglect transition dynamics, this exercise offers first insights on how the regulations interact. Then we illustrate how the interactions analyzed by our model are important for applied researchers who try to isolate the effect of labor market regulation on job flows. We show how firing and fixed costs have opposite effects on job turnover which calls for a joint analysis of regulation in empirical work.

\subsection{Complements or substitutes?}

An important question is whether labor and product market regulation are complements or substitutes in terms of welfare. In this section we investigate whether the effect of fixed costs or set-up costs changes for different levels of firing costs.

\footnotetext{
matter through their effect on the vacancy posting policy $v^{0}\left(a^{* *}, 0\right)$.

${ }^{24}$ The threshold is currently at 15 employees in Italy and 10 employees in Germany. Furthermore, in some countries, entering firms are exempt from EPL for a limited time period.
} 


\begin{tabular}{llll}
\hline \hline$F=0.09$ & $f=0.1$ & $f=0.15$ & $f=0.1$ \\
& $C=0.1$ & $C=0.1$ & $C=0.15$ \\
\hline Equilibrium Variables & $\mathbf{( 1 )}$ & $\mathbf{( 2 )}$ & $\mathbf{( 3 )}$ \\
\hline Unempl. rate $U$ (in \%) & 6.953 & 7.803 & 7.345 \\
Vacancies $V$ & 0.317 & 0.283 & 0.295 \\
Labor mkt. tightness $\theta$ & 4.552 & 3.631 & 4.021 \\
Output $Y$ & 0.366 & 0.364 & 0.363 \\
Welfare $\Omega$ & 0.307 & 0.279 & 0.306 \\
Productivity $a_{i}($ average $)$ & 0.897 & 0.925 & 0.905 \\
Prod. margins $\left(a^{* *}, a^{*}\right)$ & $(0.482,0.525)$ & $(0.528,0.598)$ & $(0.508,0.519)$ \\
Average firm size & 1.563 & 1.709 & 1.543 \\
Av. labor hoarded & 0.317 & 0.331 & 0.317 \\
Average wage & 0.111 & 0.102 & 0.105 \\
\hline \hline
\end{tabular}

Table 4: Changes in fixed or set-up costs for higher firing costs.

Fixed costs and firing costs. Before analyzing the interaction between fixed and firing costs, it is useful to notice that their effects would be independent in BC's framework. The interaction between both regulations arises because of the adjustments at the extensive margin. According to the previous sections, the selection effects of fixed costs and employment protection are qualitatively similar: they both reduce the number of operating firms in the bad state, increase firm turnover and average firm size. Quantitatively, firing costs are more important for labor hoarding whereas fixed costs have a larger effect on entry and exit.

We will show in section 5.2 that fixed costs increase the job turnover rate and thus the steady-state mobility cost per firm. But this does not necessarily induce additional welfare losses because the impact of both policies on firm selection implies that less firms need to pay the fixed costs or firing costs. This pure accounting effect reduces, and can even outweigh, the direct negative impact on welfare. Adding the change in welfare between Table 2, columns (1) and (2), and the change between Table 2, column (1), and Table 4, column (1), it appears that the welfare losses due to independent increases in firing and fixed costs add up to $16.2 \%$ 
of the initial welfare. When regulations in both product and labor markets are combined, the welfare losses decrease to 15.8\% (compare Table 2, column (1), and Table 4, column (2)). Hence, the coexistence of the two regulations slightly alleviates their individual costs.

In order to understand the reason for this complementarity better, we further decompose the total losses into changes in the aggregate cost of vacancy posting, steady-state mobility costs and fixed costs. We find that both firing and fixed costs reduce the cost of vacancy posting although this effect is minor since the absolute level of this cost is low for the chosen small parameter value of $c$. Most importantly, we find that steady-state mobility costs decrease by $3.2 \%$ if fixed costs increase from 0.1 to 0.15 (as in Table 2, columns (1) and (2)). Although the mobility costs per firm increase because of higher job turnover, the mass of firms who bears these costs is smaller and the latter effect dominates. Finally, the selection effect implies that higher firing costs increase the direct welfare losses resulting from fixed and set-up cost payments by $0.5 \%$ (for changes from Table 2 , column (1), to Table 4, column $(1)) \cdot{ }^{25}$

Set-up costs and firing costs. From the point of view of the firm, defaulting is an alternative to paying the firing costs. Therefore EPL makes bankruptcy a more attractive option. For example, comparing column (1) in Table 4 to column (1) in Table 2 shows that the incidence of bankruptcy goes up from $0.8 \%$ to $1.8 \%$ in the economy with stringent EPL. But for this option to be relevant in equilibrium, set-up costs have to be low enough to allow firms to enter the market. Hence low barriers to entry complement stringent EPL.

The results in Tables 2 and 4 illustrate this complementarity. Reducing entry costs from 0.15 to 0.1 implies a $3.1 \%$ decrease of the unemployment rate when firing costs are low (see Table 2, columns (1) and (3)), compared with 5.3\% when firing costs are high (see Table

\footnotetext{
${ }^{25}$ For $f=C=0.1$, the saved fixed costs of bankrupt firms exactly cancel the additional set-up costs of newly entering firms for given $a^{* *}$. Since $a^{* *}$ falls slightly, more firms pay the set-up cost so that the welfare loss increases.

Note also that if we rebate firing cost at the aggregate level, output still decreases with higher firing costs since bankrupt firms do not produce in the bad state (the selection effect on $a^{* *}$ and $a^{*}$ ) and labor hoarding implies lower efficiency for all operating firms. The welfare gain because of lower steady-state vacancy costs is too small to offset these effects.
} 
4, columns (1) and (3)). The higher rate of firm creation induced by low barriers to entry mitigates the higher incidence of firm destruction due to firing restrictions.

Note however, that incumbent firms like set-up cost. The fact that they make more profits is illustrated by the observation that higher set-up costs lower $a^{*}$. As mentioned above barriers to entry isolate operating firms from the competition of potential entrants. Thus, these firms can bear the firing costs "more easily". This is interesting since it points to one reason for the coexistence of both types of regulation which is beyond our model in which agents are risk-neutral and financial markets are perfect. If firms are supposed to insure workers by hoarding them in bad times, they can only do so if they remain profitable. Product market regulation generates these profits and thus makes it easier for firms to agree to policies that protect jobs in bad times.

\subsection{Job turnover and interactions between firing and fixed costs}

We have already mentioned that higher fixed and/or set-up costs increase job turnover per firm. As the competition for workers is alleviated by the selection effect, the costs of adjusting the labor force decrease. Thus firms have less incentive to smooth out their labor demand schedule. Conversely, it is well known that firing costs imply less labor mobility at both the aggregate and firm level. These insights are illustrated in Table 5. The table reports the rate of job finding, the aggregate job flows ${ }^{26}$ along with the rates of job turnover and job turnover per firm. Table 5 shows that fixed costs decrease whereas firing costs increase the job finding rate. Firing costs do reduce job flows because of the lower unemployment rate. Fixed costs have almost no effect on aggregate job flows as the smaller transition rate is compensated by the increase in the size of the unemployment pool. Since the flows out of the employment pool are nearly constant whereas the number of employees is smaller, it follows that the job turnover rate is an increasing function of fixed costs. The job turnover rate per firm is also

\footnotetext{
${ }^{26}$ Notice that job flows and worker flows are indistinguishable in the current formulation of the model since we have excluded job-to-job transitions. Moreover, the job turnover rates are slightly higher than the empirical counterparts reported for the US (see Davis and Haltiwanger, 1999, Table 2). This is because we assume larger values for $v$ in our calibration than in the data to ensure that firms with $a_{i}>a^{*}$ are always at the firing margin in the bad state (see the discussion of the calibration in Section 3).
} 


\begin{tabular}{lllll}
\hline \hline \multicolumn{5}{l}{$U S$} \\
& $F=0.04$ & $F=0.09$ & $F=0.04$ & $F=.09$ \\
& $f=0.1$ & $f=0.1$ & $f=0.15$ & $f=0.15$ \\
\hline Equilibrium Variables & $\mathbf{( 1 )}$ & $\mathbf{( 2 )}$ & $\mathbf{( 3 )}$ & $\mathbf{( 4 )}$ \\
\hline Job finding rate & 5.287 & 5.334 & 4.760 & 4.764 \\
Job flows & 0.403 & 0.371 & 0.400 & 0.372 \\
Job turnover rate & 0.436 & 0.399 & 0.437 & 0.403 \\
Job turnover rate / firm & 0.645 & 0.601 & 0.692 & 0.646 \\
\hline \hline
\end{tabular}

Table 5: The effect of firing and fixed costs on turnover.

increasing for the same reasons, but in this case the effect of fixed costs is strong enough so as to completely offset the "sclerosis" generated by EPL. The impact of set-up costs on the job turnover rate per firm is similar but smaller. Yet, their effect on job turnover is ambiguous in general because set-up costs also reduce the number of "non-permanent" firms.

The implication of the model that product and labor market regulation have opposite effects on job turnover is a priori consistent with empirical evidence that turnover rates across countries are very loosely related to the stringency of EPL. This empirical fact has led Bertola and Rogerson (1997) to argue that the greater compression of wages in Europe than in the US can compensate the differences in EPL and so explain the similarity of the turnover rates. The model proposed in this paper suggests that more product market regulation in Europe is an alternative explanation. In the light of Table 5, the lack of conclusive evidence might be partly explained by the countervailing effects of EPL and PMR. ${ }^{27}$

\footnotetext{
${ }^{27}$ Preliminary empirical results provide weak support for this prediction of the model. We regress job turnover statistics taken from the OECD Employment Outlook 1996 on cross-country indexes for both types of regulations (Nicoletti et al., 1999). Considered separately, the EPL and PMR indexes are not significant at all and have a negative coefficient. When both EPL and PMR indicators are included as regressors, the explanatory power of the regression increases. Moreover, the coefficients have the desired negative sign for EPL and positive sign for PMR. Nevertheless, both variables remain non-significant at conventional levels. The small sample size, the stylized nature of the indexes and, most importantly, the fact that the indexes are nearly collinear probably explain the lack of conclusive evidence. Thus, although a preliminary look at the data does not contradict the model's prediction, further empirical research is needed in order to ascertain
} 


\section{Conclusions}

The model analyzed in this paper extends the framework proposed in Bertola and Caballero (1994) by considering that, besides idiosyncratic fluctuations in business conditions, firms also differ with respect to their permanent technological productivity. These transitory and permanent differences explain why some firms decide to enter the market while others prefer to remain inactive. Accordingly the equilibrium exhibits both firm and job turnover.

The distinction between the extensive and intensive margin has allowed us to generate some novel results compared with the literature, especially models based on the "onefirm-one-worker" assumption. Most importantly, the model illustrates how the interactions between labor and product market regulation crucially depend on the link between both margins of adjustment. We find that firing costs are quantitatively most important for the hiring and firing margin whereas fixed and set-up cost matter more for the entry and exit margin. Nevertheless, both policies also matter for the respective other margin. Strikingly enough, the effects of firing restrictions on the intensive and extensive margin are of opposite signs: they reduce job turnover and amplify firm turnover. Conversely, job turnover is stimulated by administrative regulations and to a lesser extent by barriers to entry.

These countervailing effects call for a joint analysis of regulation in empirical work, as their interactions may explain why empirical studies using cross-country flow data have failed to document the strong negative relationship between EPL and job flows predicted by the theory. Given that both regulations are strongly positively correlated, if PMR stimulates job reallocation, the negative impact of EPL needs not be evident in cross-country data.

The model also has some clear predictions about the design of regulation policies. Fixed and set-up costs interact negatively by reducing both the incentives to enter the market and the capacity of potential entrants to do so. High firing costs and low set-up costs complement each other because the bankruptcy option is a profitable alternative to paying the firing costs for firms with low permanent productivity. This motivates why EPL is not applied to small firms in countries with strict employment protection legislation. Productive incumbent firms, however, benefit from higher set-up costs since fewer firms produce in equilibrium whether or not the positive relationship between job turnover and PMR can be documented in the data. 
which reduces the congestion externality. Thus, if a government wants to introduce firing costs, it could "buy" the support of these firms by compensating them with entry barriers. Overall, our results suggest that considering interactions between product and labor market regulation is important for policy design as well as for understanding the different labor market outcomes across countries.

The proposed framework lends itself naturally to many extensions. In ongoing research we investigate the implications of our model on the employment and wage distributions across firms with different size. Also the predictions for the effect of firing costs on the extensive margin deserve further empirical investigation with firm-level data as in Autor, Kerr and Kugler (2005). Before taking the model to the data, however, it would be useful to allow for a more realistic shock structure. The shocks in our model are rather big, much larger than most of the shocks which hit firms in reality. Accordingly our measure of firing costs relates more closely to restrictions on collective dismissal. Introducing techniques developed in Bertola and Garibaldi (2001) would allow for a finer shock structure and so more realistic predictions.

From a theoretical perspective it is worth analyzing optimal regulation if the social planner can condition this regulation on firm size. Finally, we have taken the market power of firms as given in our analysis. In other terms, we have interpreted the decreasing marginal revenue schedule of firms as technological and not as reflecting market power. Further research could extend the model to endogenize market power by making it an explicit function of the number of operating firms. This would certainly introduce additional channels of interaction between both policies. 


\section{Appendix}

\section{Workers.}

Given that workers are homogenous, the asset value of employment solely depends on the firm characteristics. Workers receive a utility flow $b$ if unemployed and an endogenous wage $w_{i}^{g, n}(\tau)$ in the good state or $w_{i}^{b, 1}$ if employed in the bad state by a labor hoarding firm.

The asset value of the representative unemployed worker in steady state is

$$
r W^{u}=b+\theta q(\theta)\left(\bar{W}^{e}-W^{u}\right)
$$

where the Poisson hazard of finding a job is $\theta q(\theta)$; and $\bar{W}^{e}$ is the expected asset value of being matched to one of the posted vacancies. This expected value depends on the realized distribution of posted vacancies. Note that $W^{u}$ by definition is independent of the type of firm $i$. The value of being in a bad job is

$$
r W^{b, 1}=w_{i}^{b}+v\left(W_{i}^{g, 1}(0)-W^{b}\right)
$$

where $n$ has been set to one since only "labor-hoarding" firms employ workers in the bad state. The asset value of employment in a good firm which has been $\tau$ periods in the good state is

$$
r W_{i}^{g, n}(\tau)=w_{i}^{g, n}(\tau)+\delta\left(W^{u}-W_{i}^{g, n}(\tau)\right)+\dot{W}_{i}^{g, n}(\tau)
$$

where $\delta$ is the exogenous Poisson hazard of a bad shock. As shown in BC, p. 441-442, nonenforceability of long-term contracts implies that the asset value of a worker in a firm with low productivity $\varepsilon_{b}$ is equal to the outside option $W^{u}$ (firms can credibly threaten workers to fire them otherwise). Thus, $W^{b}$ is also independent of firm-specific productivity $a_{i}$ since unemployed workers and workers in firms with temporarily low productivity have the same expected discounted utility. Equation (A2) implies that the wage in the bad state $w_{i}^{b}$ will absorb differences in $W_{i}^{g, 1}(0)$.

\section{Wage determination.}

Wages are determined by Nash bargaining between the worker and the firm. Nonenforceability of contracts implies that all workers in a given firm earn the same wage. 
However, wages between firms differ as long as workers have some bargaining power, $\beta>0$. Wages differ for firms in the good state depending on the time they have spend in the good state and the number of workers they have hired in this time. As is standard the Nash bargain implies that

$$
\beta\left(S_{i}^{g, n}(\tau)-S^{o}\right)=(1-\beta)\left(W_{i}^{g, n}(\tau)-W^{u}\right)
$$

where the shadow value of posting a vacancy $S^{o}$ is zero (the shadow value of hiring a worker equals the flow cost of posting the vacancy discounted by the probability that the vacancy is matched to a worker).

Plugging the shadow value of hiring a worker (6) into the optimality condition of the Nash bargain (A4), we get

$$
W_{i}^{g, n}(\tau)=W^{u}+\frac{\beta}{1-\beta} \frac{c v_{i}^{n}(\tau)}{q(\theta)}
$$

and thus

$$
\dot{W}_{i}^{g, n}(\tau)=\frac{\beta}{1-\beta} \frac{c \dot{v}_{i}^{n}(\tau)}{q(\theta)}
$$

where dots denote time derivatives. The outside option of workers does not change as firms experience good times, but the number of posted vacancies does. Inserting these two expressions into (A3), we get

$$
w_{i}^{g, n}(\tau)=r W^{u}+\frac{\beta c}{1-\beta} \frac{(r+\delta) v_{i}^{n}(\tau)-\dot{v}_{i}^{n}(\tau)}{q(\theta)} .
$$

Wages of "non-permanent" firms. Reinserting the explicit expression for the shadow value of a hired worker (7) into (A6) yields

$$
w_{i}^{g, 0}(\tau)=r W^{u}+\frac{\beta}{1-\beta}\left(\eta_{i}^{g}-\sigma l_{i}^{0}(\tau)-\omega_{i}^{g, 0}(\tau)\right) .
$$

Making explicit the dependence of wages on employment $w_{i}^{g, 0}=g^{0}\left(l_{i}^{0}(\tau)\right)$. Since $\omega_{i}^{g, n}(\tau)=$ $g^{n}\left(l_{i}^{n}(\tau)\right)+g_{l}^{n}\left(l_{i}^{n}(\tau)\right) l_{i}^{n}(\tau)$, we find that the following condition must hold

$$
g^{0}\left(l_{i}^{0}(\tau)\right)=r W^{u}+\frac{\beta}{1-\beta}\left(\eta_{i}^{g}-\sigma l_{i}^{0}(\tau)-g^{0}\left(l_{i}^{0}(\tau)\right)-g_{l}^{0}\left(l_{i}^{0}(\tau)\right) l_{i}^{0}(\tau)\right) .
$$

This first-order differential equation has the linear solution

$$
w_{i}^{g, 0}(\tau)=(1-\beta) r W^{u}+\beta \eta_{i}^{g}-\frac{\beta \sigma}{1+\beta} l_{i}^{0}(\tau) .
$$


Wages of "labor-hoarding" firms. Solving the explicit expression for the shadow value of a hired worker (9) and plugging this into (A6) results in

$$
w_{i}^{g, 1}(\tau)=r W^{u}+\frac{\beta}{1-\beta}\left(\eta_{i}^{g}-\sigma l_{i}^{1}(\tau)-\omega_{i}^{g, 1}(\tau)-\delta F\right) .
$$

Solving for $w_{i}^{g, 1}$ in terms of $l_{i}^{1}(\tau)$ as before finally yields

$$
w_{i}^{g, 1}(\tau)=(1-\beta) r W^{u}+\beta\left(\eta_{i}^{g}-\delta F\right)-\frac{\beta \sigma}{1+\beta} l_{i}^{1}(\tau) .
$$

Wages in good firms are a weighted average of the workers outside option and the firm's surplus net of expected firing costs.

\section{Optimal labor demand schedules.}

By definition

$$
\omega_{i}^{g, n}(\tau)=w_{i}^{g, n}(\tau)-\frac{\beta \sigma}{1+\beta} l_{i}^{n}(\tau) .
$$

Note the incentive of firms to reduce the surplus appropriated by workers by increasing employment. This incentive is stronger the larger is $\beta$ and $\sigma$.

Reinserting this expression into (7) and (9), differentiating with respect to $\tau$, we get (notice that $\theta$ does not change in the steady state)

$$
-\dot{w}_{i}^{g, n}(\tau)-\frac{\sigma}{1+\beta} \dot{l}_{i}^{n}(\tau)+\frac{c \ddot{v}_{i}^{n}(\tau)}{q(\theta)}=(r+\delta) \frac{c \dot{v}_{i}^{n}(\tau)}{q(\theta)} .
$$

Differentiating equation (A6) with respect to $\tau$ we have

$$
\dot{w}_{i}^{g, n}(\tau)=r W^{u}+\frac{\beta c}{1-\beta} \frac{(r+\delta) \dot{v}_{i}^{n}(\tau)-\ddot{v}_{i}^{n}(\tau)}{q(\theta)} .
$$

Using the two equations to substitute out $\dot{w}_{i}^{g, n}(\tau)$,

$$
-\frac{\beta c}{1-\beta} \frac{(r+\delta) \dot{v}_{i}^{n}(\tau)-\ddot{v}_{i}^{n}(\tau)}{q(\theta)}+\frac{c \ddot{v}_{i}^{n}(\tau)}{q(\theta)}-(r+\delta) \frac{c \dot{v}_{i}^{n}(\tau)}{q(\theta)}-\frac{\sigma}{1+\beta} l^{n}(\tau)=0 .
$$

Using (5), replacing $q(\theta)$ by $\xi \theta^{\gamma}$ and rearranging yields

$$
\ddot{v}_{i}^{n}(\tau)-(r+\delta) \dot{v}_{i}^{n}(\tau)-\sigma \frac{1-\beta}{1+\beta} \frac{\xi^{2} \theta^{2 \gamma}}{c} v_{i}=0 .
$$

The solution of this second-order differential equation that satisfies $\lim _{\tau \rightarrow \infty} v_{i}^{n}(\tau)=0$ is

$$
v_{i}^{n}(\tau)=v_{i}^{n}(0) e^{-\lambda \tau} \text { with } \lambda=1 / 2\left(-(r+\delta)+\sqrt{(r+\delta)^{2}+4 \sigma \frac{1-\beta}{1+\beta} \frac{\xi^{2} \theta^{2 \gamma}}{c}}\right) .
$$


Permanent differences between firms, $a_{i}$, matter only for the absolute number of posted vacancies but not for the behavior of the vacancy policy over time ( $\lambda$ would depend on $i$ if we allowed $\sigma$ to differ across firms). The rate of convergence is also independent of firm entry and exit $(n=0,1)$.

Given the exogenous destruction rate $\delta$, open vacancies are distributed exponentially over $\tau$ with parameter $\delta+\lambda$ independently of the value of $a_{i}$. Equation (A5) then implies that the expected gain from finding a job in a good firm is

$$
\begin{aligned}
\bar{W}^{e}-W^{u} & =\frac{\beta}{1-\beta} \frac{c}{q(\theta)}(\delta+\lambda)\left(\frac{1}{\left.1-U\left(a^{* *} \wedge a^{*}\right)\right)}\right)\left[\begin{array}{c}
\int_{a^{* *} \wedge a^{*}}^{a^{*}}\left(\int_{0}^{\infty} v_{i}^{0}(\tau) e^{-(\delta+\lambda) \tau} d \tau\right) u(a) d a \\
+\int_{a^{*}}^{a}\left(\int_{0}^{\infty} v_{i}^{1}(\tau) e^{-(\delta+\lambda) \tau} d \tau\right) u(a) d a
\end{array}\right] \\
& =\frac{\beta}{1-\beta} \frac{c}{q(\theta)} \frac{\delta+\lambda}{\delta+2 \lambda}\left(\frac{\int_{a^{* *} a^{*}}^{a^{*}} v_{i}^{0}(0) u(a) d a+\int_{a^{*}}^{\bar{a}} v_{i}^{1}(0) u(a) d a}{\left.1-U\left(a^{* *} \wedge a^{*}\right)\right)}\right) .
\end{aligned}
$$

where $a^{* *} \wedge a^{*} \equiv \min \left\{a^{* *}, a^{*}\right\}, u(a)$ and $U(a)$ respectively denote the PDF and CDF of $a$. The second equality follows from $v_{i}^{n}(\tau)=v_{i}^{n}(0) e^{-\lambda \tau}$ and the fact that $a_{i}$ and $\tau$ are independently distributed. Notice that the distribution is normalized by the actual mass of operating firms $1-U\left(a^{* *} \wedge a^{*}\right)$ since the expected asset value is conditioned on the formation of a match.

Moreover, equation (A1) implies that

$$
r W^{u}=b+c \theta \frac{\beta}{1-\beta} \frac{\delta+\lambda}{\delta+2 \lambda}\left(\frac{\int_{a^{* *} \wedge a^{*}}^{a^{*}} v_{i}^{0}(0) u(a) d a+\int_{a^{*}}^{\bar{a}} v_{i}^{1}(0) u(a) d a}{\left.1-U\left(a^{* *} \wedge a^{*}\right)\right)}\right) .
$$

and equation (A2) implies

$$
r W^{b, 1}=w_{i}^{b}+v\left(W_{i}^{g, 1}(0)-W^{b, 1}\right)=w_{i}^{b}+v \frac{\beta}{1-\beta} \frac{c v_{i}^{1}(0)}{q(\theta)} .
$$

where the second equality follows from equation (A5). In equilibrium $W^{u}=W^{b, 1}$ and thus

$$
w_{i}^{b}=b+\frac{\beta}{1-\beta} c\left(\theta \frac{\delta+\lambda}{\delta+2 \lambda}\left(\frac{\int_{a^{* *} a^{*}}^{a^{*}} v_{i}^{0}(0) u(a) d a+\int_{a^{*}}^{\bar{a}} v_{i}^{1}(0) u(a) d a}{\left.1-U\left(a^{* *} \wedge a^{*}\right)\right)}\right)-\frac{v}{q(\theta)} v_{i}^{1}(0)\right) .
$$

The wage in the bad state depends positively on the total number of posted vacancies which increase the outside option; but negatively on the expected number of vacancies posted in the own firm $i$ if good times arrive. Workers are willing to take larger wage cuts in bad times 
if this is compensated in good times. Equations (A6) and (A9) imply

$$
w_{i}^{g, n}(\tau)=r W^{u}+\frac{\beta c}{1-\beta} \frac{(r+\delta+\lambda) v_{i}^{n}(0) e^{-\lambda \tau}}{q(\theta)} .
$$

Plugging in $W^{u}$, we get

$$
w_{i}^{g, n}(\tau)=b+\frac{\beta}{1-\beta} c\left(\theta \frac{\delta+\lambda}{\delta+2 \lambda}\left(\frac{\int_{a^{* *} a^{*}}^{a^{*}} v_{i}^{0}(0) u(a) d a+\int_{a^{*}}^{\bar{a}} v_{i}^{1}(0) u(a) d a}{\left.1-U\left(a^{* *} \wedge a^{*}\right)\right)}\right)+\frac{(r+\delta+\lambda) e^{-\lambda \tau}}{q(\theta)} v_{i}^{n}(0)\right) .
$$

Note that the wage in good times depends positively on $v_{i}^{n}(0)$. As $\tau \rightarrow \infty$ all workers earn the same wage as firms exploit their monopsony power and hire until

$$
w^{g, n}(\tau \rightarrow \infty) \equiv \lim _{\tau \rightarrow \infty} w_{i}^{g, n}=b+\frac{\beta}{1-\beta} c \theta \frac{\delta+\lambda}{\delta+2 \lambda}\left(\frac{\int_{a^{* *} \wedge a^{*}}^{a^{*}} v_{i}^{0}(0) u(a) d a+\int_{a^{*}}^{\bar{a}} v_{i}^{1}(0) u(a) d a}{\left.1-U\left(a^{* *} \wedge a^{*}\right)\right)}\right) .
$$

To sum up: workers in firms with high permanent productivity $a_{i}>a^{*}$ earn lower wages in bad times, higher wages upon arrival of good times and the same wage as $\tau \rightarrow \infty$.

Employment and boundary conditions for $v_{i}^{n}(0)$ and $l_{i}^{n}(0)$.

The employment and vacancy schedules are fully characterized by the initial conditions $v_{i}^{n}(0)$ and $l_{i}^{n}(0)$ since $v_{i}^{n}(\tau)=v_{i}^{n}(0) e^{-\lambda \tau}$ and

$$
l_{i}^{n}(\tau)=l_{i}^{n}(0)+\frac{q(\theta)}{\lambda}\left(1-e^{-\lambda \tau}\right) v_{i}^{n}(0) .
$$

Initial vacancy posting of "non-permanent" firms. Since $l_{i}^{0}(0)=0$, we only need one boundary condition to characterize the optimal labor demand schedule. Since all workers are shed, there is no need to ensure that workers are indifferent between employment and unemployment. The value of $v_{i}^{0}(0)$ can be determined noticing that (A7) and (A11) must be equal, so that

$$
\frac{c}{1-\beta} \frac{(r+\delta+\lambda)}{q(\theta)} v_{i}^{0}(0)=\eta_{i}^{g, 0}-b-r W^{u} .
$$

Initial vacancy posting of "labor hoarding" firms. For these firms, $l_{i}(0)$ differs from zero so we need to determine two boundary conditions. Equation (8) together with the result that workers are indifferent between employment and unemployment in the bad state and $\omega_{i}^{b, 1}(0)=w_{i}^{b}$ implies

$$
v v_{i}^{1}(0)=\frac{q(\theta)}{c}\left(\sigma l_{i}(0)-\left(\eta_{i}^{b, 1}+(v+r) F-w_{i}^{b}\right)\right) .
$$


As before, the second boundary condition follows from equating (A8) and (A12) using (A10):

$$
(1-\beta) r W^{u}+\beta\left(\eta_{i}^{g, 1}-\delta F\right)-\frac{\beta \sigma}{1+\beta} l_{i}^{1}(0)=w_{i}^{b}+\frac{\beta c}{1-\beta} \frac{v+(r+\delta+\lambda)}{q(\theta)} v_{i}^{1}(0) .
$$

Since $W^{u}=W^{b, 1}$

$$
\frac{c}{1-\beta} \frac{\beta v+r+\delta+\lambda}{q(\theta)} v_{i}^{1}(0)=-\frac{\sigma}{1+\beta} l_{i}^{1}(0)+\left(\eta_{i}^{g, 1}-\delta F-w_{i}^{b}\right) .
$$

Inserting, $w_{i}^{b}$ from (A10), the two boundary conditions can be used to solve for $v_{i}^{1}(0)$ and $l_{i}^{1}(0)$ (for given $a^{*}$ ), and average vacancies and employment (integrating over $a \in\left[a^{* *} \wedge a^{*} ; \bar{a}\right]$ ). This completes the characterization of firm $i$ 's optimal policies. It remains to close the model by determining the aggregate stock of vacancies $V$ and employment $L$ and thus $\theta$.

\section{Equilibrium.}

In steady state the number of firms turning good has to equal the number of firms turning bad (for each $a_{i}$ ). Thus the proportion of firms in the good and bad state, $\phi_{g}$ and $\phi_{b}$ respectively, are given by

$$
v \phi_{b}=\delta \phi_{g}
$$

and

$$
\phi_{b}+\phi_{g}=1
$$

so that

$$
\phi_{b}=\frac{\delta}{\delta+v} \text { and } \phi_{g}=\frac{v}{\delta+v} .
$$

Given that the density of $\tau$ is exponentially distributed, we get

$$
V=\frac{v \delta}{\delta+v} \int_{a^{* *} \wedge a^{*}}^{\bar{a}} \int_{0}^{\infty} v_{i}^{n}(\tau) e^{-\delta \tau} d \tau u(a) d a=\frac{v}{\delta+v} \frac{\delta}{\delta+\lambda} \int_{a^{* *} \wedge a^{*}}^{\bar{a}} v_{i}^{n}(0) u(a) d a .
$$

and

$$
L=\frac{v \delta}{\delta+v} \int_{a^{* *} \wedge a^{*}}^{\bar{a}} \int_{0}^{\infty} l_{i}^{n}(\tau) e^{-\delta \tau} d \tau d U(a)+\frac{\delta}{\delta+v} \int_{a^{*}}^{\bar{a}} l_{i}^{1}(0) u(a) d a .
$$

Plugging in $l_{i}^{n}(\tau)$ we get

$$
L=\frac{v q(\theta)}{(\delta+v)(\delta+\lambda)} \int_{a^{* *} \wedge a^{*}}^{\bar{a}} v_{i}^{n}(0) u(a) d a+\int_{a^{*}}^{\bar{a}} l_{i}^{1}(0) u(a) d a,
$$


where the aggregate employment level depends negatively on $a^{* *}$ and $a^{*}$.

\section{Steady-state employment distribution.}

Let $T(l, a)$ denote the time elapsed in the good state such that a firm with characteristic $a$ has a workforce equal to $l$. Given that

$$
l(T, a)=l^{n}(0, a)+q(\theta)\left(\frac{1-e^{-\lambda T}}{\lambda}\right) v^{n}(0, a),
$$

where $n=1$ when $a$ is such that the firm hoards labor and 0 otherwise. Accordingly

$$
T(l, a)=-\left(\frac{1}{\lambda}\right) \ln \left(1-\frac{\left(l-l^{n}(0, a)\right) \lambda}{v^{n}(0, a) q(\theta)}\right) .
$$

As business conditions switch to the bad state at the Poisson rate $\delta$, the employment density $\mu\left(l \mid a_{i}\right)$ reads

$$
\mu\left(l \mid a_{i}\right)=\left\{\begin{array}{c}
\frac{\delta}{\delta+v} \text { if } l=l^{n}\left(0, a_{i}\right) \\
\left(\frac{v}{\delta+v}\right) \delta e^{-\delta\left(T\left(l, a_{i}\right)\right)} \text { if } l \in\left(l^{n}\left(0, a_{i}\right), l^{n}\left(0, a_{i}\right)+\frac{q(\theta)}{\lambda} v^{n}\left(0, a_{i}\right)\right) \\
0 \text { if } l \notin\left[l^{n}\left(0, a_{i}\right), l^{n}\left(0, a_{i}\right)+\frac{q(\theta)}{\lambda} v^{n}\left(0, a_{i}\right)\right)
\end{array}\right.
$$

According to Kolmogorov's forward equation

$$
\frac{\partial \mu\left(l \mid a_{i}\right)}{\partial t}=-\frac{\partial \mu\left(l \mid a_{i}\right)}{\partial l} l_{i}^{n}-\delta \mu\left(l \mid a_{i}\right)
$$

the steady-state condition $\frac{\partial \mu\left(l \mid a_{i}\right)}{\partial t}=0$ is satisfied when

$$
-\frac{\partial \mu\left(l \mid a_{i}\right)}{\partial l} l_{i}^{n}=\delta \mu\left(l \mid a_{i}\right)
$$

Differentiating the density above yields for all $l \in\left(l^{n}\left(0, a_{i}\right), l^{n}\left(0, a_{i}\right)+\frac{q(\theta)}{\lambda} v^{n}\left(0, a_{i}\right)\right)$

$$
-\frac{\partial \mu\left(l \mid a_{i}\right)}{\partial l}=\delta\left[v^{n}\left(0, a_{i}\right) q(\theta)-\left(l-l^{n}\left(0, a_{i}\right)\right) \lambda\right]^{-1} \mu\left(l \mid a_{i}\right) .
$$

Reinserting the expression for $\dot{l}_{i}^{n}$

$$
\dot{l}_{i}^{n}=q(\theta) v_{i}^{n}(l)=q(\theta) v^{n}\left(0, a_{i}\right) e^{-\lambda T\left(l, a_{i}\right)}=v^{n}\left(0, a_{i}\right) q(\theta)-\left(l-l^{n}\left(0, a_{i}\right)\right) \lambda,
$$

proves that the Kolmogorov forward condition is satisfied by the proposed steady-state distribution. In other words, when employment is distributed according to $\mu\left(l \mid a_{i}\right)$, inflows and outflows for any employment level balance out. 


\section{Output and Welfare.}

Each firm in the good state has a "production-equivalent" flow

$$
y_{i}^{g, n} \equiv \eta_{i}^{g} l_{i}^{n}(\tau)-\frac{\sigma}{2} l_{i}^{n}(\tau)^{2}-\frac{c}{2} v_{i}^{n}(\tau)^{2}-\delta F\left(l_{i}^{n}(\tau)-l_{i}^{n}(0)\right) n
$$

Firms in the good state bear a steady-state mobility cost $\delta F\left(l_{i}^{1}(\tau)-l_{i}^{1}(0)\right)$ if $n=1$, and costs of vacancy posting $c v^{n}(\tau)^{2} / 2$ (below we add the fixed cost $f$ which all firms have to pay). Instead each firm in the bad state has a "production-equivalent" flow

$$
y_{i}^{b, n} \equiv n\left(\eta_{i}^{b} l_{i}^{n}(0)-\frac{\sigma}{2} l_{i}^{n}(0)^{2}\right) .
$$

Thus, gross output is defined as

$$
\begin{aligned}
Y= & \frac{v}{v+\delta}\left[\begin{array}{c}
\int_{a^{* *} a^{*}}^{a^{*}}\left(\int_{0}^{\infty} \delta e^{-\delta \tau}\left(\eta_{i}^{g} l_{i}^{0}(\tau)-\frac{\sigma}{2} l_{i}^{0}(\tau)^{2}-\frac{c}{2} v_{i}^{0}(\tau)^{2}\right) d \tau\right) u(a) d(a)+ \\
\int_{a^{*}}^{\bar{a}}\left(\int_{0}^{\infty} \delta e^{-\delta \tau}\left(\left(\eta_{i}^{g}-\delta F\right) l_{i}^{1}(\tau)-\frac{\sigma}{2} l_{i}^{1}(\tau)^{2}-\frac{c}{2} v_{i}^{1}(\tau)^{2}\right) d \tau\right) u(a) d(a)
\end{array}\right] \\
& +\frac{\delta}{v+\delta} \int_{a^{*}}^{\bar{a}}\left(\left(\eta_{i}^{b}+v F\right) l_{i}^{1}(0)-\frac{\sigma}{2} l_{i}^{1}(0)^{2}\right) u(a) d(a),
\end{aligned}
$$

up to a constant of integration that can be neglected if profits are zero for firms that do not use labor. We compute welfare $\Omega$ adding the production-equivalent flow $b$ for all unemployed workers and subtracting $f$ for all firms in the market, as well as the set-up costs incurred by the firms which enter the market, so that

$$
\Omega=Y+b U-\left(\frac{v}{v+\delta}\right) \int_{a^{* *} \wedge a^{*}}^{a^{*}}(f+\delta C) u(a) d(a)-\int_{a^{*}}^{\bar{a}} f u(a) d(a) .
$$

Plugging in the expression for $l_{i}^{n}(\tau)$ and $v_{i}^{n}(\tau)$, the first integral in $Y$ reads

$$
\begin{aligned}
& \int_{0}^{\infty} \delta e^{-\delta \tau}\left(\eta_{i}^{g} l_{i}^{0}(\tau)-\frac{\sigma}{2} l_{i}^{0}(\tau)^{2}-\frac{c}{2} v_{i}^{0}(\tau)^{2}\right) d \tau \\
= & \frac{q(\theta)}{\delta+\lambda} \eta_{i}^{g} v_{i}^{0}(0)-\frac{\sigma q(\theta)^{2}}{(\lambda+\delta)(2 \lambda+\delta)} v_{i}^{0}(0)^{2}-\frac{\delta}{\delta+2 \lambda} \frac{c}{2} v_{i}^{0}(0)^{2} .
\end{aligned}
$$

Integrating this expression over $a \in\left[a^{* *} \wedge a^{*} ; a^{*}\right]$ allows us to compute the first term of $Y$, whereas

$$
\begin{aligned}
& \int_{0}^{\infty} \delta e^{-\delta \tau}\left(\left(\eta_{i}^{g}-\delta F\right) l_{i}^{1}(\tau)-\frac{\sigma}{2} l_{i}^{1}(\tau)^{2}-\frac{c}{2} v_{i}^{1}(\tau)^{2}\right) d \tau \\
= & \left(\eta_{i}^{g}-\delta F\right) l_{i}^{1}(0)+\frac{q(\theta)}{\delta+\lambda}\left(\eta_{i}^{g}-\delta F\right) v_{i}^{1}(0)-\frac{\sigma}{2} l_{i}^{1}(0)^{2} \\
& -\frac{\sigma q(\theta)^{2}}{(\lambda+\delta)(2 \lambda+\delta)} v_{i}^{1}(0)^{2}-\frac{\sigma}{\delta+\lambda} q(\theta) l_{i}^{1}(0) v_{i}^{1}(0)-\frac{\delta}{\delta+2 \lambda} \frac{c}{2} v_{i}^{1}(0)^{2} .
\end{aligned}
$$


which can be integrated over $a \in\left[a^{*} ; \bar{a}\right]$ to compute the second term of $Y$.

\section{References}

[1] Abrahams, Katherine G. and Robert Shimer (2002): "Changes in Unemployment Duration and Labor Force Attachment", in: Krueger, Alan and Robert Solow (eds.), The Roaring Nineties: Can Full Employment Be Sustained?, Russell Sage and Century Foundations, 367-420.

[2] Alesina, Alberto, Silvia Ardagna, Giuseppe Nicoletti and Fabio Schiantarelli (2005): "Regulation and Investment", Journal of the European Economic Association, vol. 3, 791-825.

[3] Autor, David H., John J. Donohue III and Stewart J. Schwab (2006): "The Costs of Wrongful-Discharge Laws", Review of Economics and Statistics, vol. 88, May 2006, forthcoming.

[4] Autor, David H., William R. Kerr and Adriana D. Kugler (2005): "Do Employment Protections Reduce Productivity? Evidence from U.S. States", Harvard University, mimeo.

[5] Belviso, Francesco (2005): "Firing Costs and Unemployment: considering bankruptcy in a matching model", Princeton University, mimeo.

[6] Bentolila, Samuel and Giuseppe Bertola (1990): "Firing Costs and Labour Demand: How Bad is Eurosclerosis?", Review of Economic Studies, vol. 57, 381-402.

[7] Bertola, Giuseppe and Ricardo J. Caballero (1994): "Cross-Sectional Efficiency and Labour Hoarding in a Matching Model of Unemployment", Review of Economic Studies, vol. $61,435-56$.

[8] Bertola, Giuseppe and Pietro Garibaldi (2001): "Wages and the Size of Firms in Dynamic Matching Models", Review of Economic Dynamics, vol. 4, 335-68. 
[9] Bertola, Giuseppe and Richard Rogerson (1997): "Institutions and Labor Reallocation", European Economic Review, vol. 41, 1147-71.

[10] Blanchard, Olivier J. and Francesco Giavazzi (2003): "Macroeconomic Effects of Regulation and Deregulation in Goods and Labor Markets", Quarterly Journal of Economics, vol. $118,879-908$.

[11] Cahuc, Pierre, Francois Marque and Etienne Wasmer (2004): "A Theory of Wages and Labor Demand with Intrafirm Bargaining and Matching Frictions", mimeo, CREST, Paris.

[12] Davis, Steven J., John C. Haltiwanger and Scott Schuh (1996): Job Creation and Job Destruction, MIT Press, Cambridge (Massachusetts).

[13] Davis, Steven J., and John C. Haltiwanger (1999): “Gross Job Flows", in: Handbook of Labor Economics, vol. 3B, Ashenfelter, Orley and David Card (eds.), Elsevier, Amsterdam.

[14] Ebell, Monique and Christian Haefke (2004): "The Missing Link: Product Market Regulation, Collective Bargaining and the European Unemployment Puzzle", Unversitat Pompeu Fabra, mimeo.

[15] Flinn, Christopher (2005): "Minimum Wage Effects on Labor Market Outcomes under Search, Matching, and Endogenous Contact Rates", New York University, mimeo.

[16] Garibaldi, Pietro and Giovanni L. Violante (2005): "The Employment Effects of Severance Payments With Wage Rigidities", Economic Journal, vol. 115, 799-832.

[17] Hamermesh, Daniel S. (1993): Labor Demand, Princeton University Press, Princeton.

[18] Hopenhayn, Hugo and Richard Rogerson (1993): "Job Turnover and Policy Evaluation: a general equilibrium analysis", Journal of Political Economy, vol. 101, 915-38.

[19] Ljungqvist, Lars and Thomas Sargent (1998): "The European Unemployment Dilemma", Journal of Political Economy, vol. 106, 514-50. 
[20] Lopez-Garcia, Paloma (2003): "Labour Market Performance and Start-up Costs: OECD Evidence", CESifo Working Paper Series, No. 849.

[21] Mortensen, Dale and Christopher Pissarides (2003): "Taxes, Subsidies and Equilibrium Labor Market Outcomes", in: Designing Inclusion: Tools to Raise Low-End Pay and Employment in Private Enterprise, Phelps, Edmund S. (ed.), Cambridge University Press, Cambridge.

[22] Nicoletti, Giuseppe, Stefano Scarpetta and Olivier Boylaud (1999): "Summary Indicators of Product Market Regulation with an Extension to Employment Protection Legislation", OECD Economics Department Working Papers No. 226, OECD, Paris.

[23] OECD (1999, 2004): "Employment Protection Regulation and Labour Market Performance", Employment Outlook, ch. 2, OECD, Paris.

[24] Petrongolo, Barbara and Christopher Pissarides (2000): "Looking into the Black Box: A Survey of the Matching Function", Journal of Economic Literature, vol. 39, 390-431.

[25] Pissarides, Christopher (2000): Equilibrium Unemployment Theory, second edition, MIT Press, Cambridge (Massachusetts).

[26] Smith, Eric (1999): "Search, Concave Production and Optimal Firm Size", Review of Economic Dynamics, vol. 2, 456-71.

[27] Stole, Lars A. and Jeffrey Zwiebel (1996a): "Intra-Firm Bargaining under Non-Binding Contracts", Review of Economic Studies, vol. 63, 375-410.

[28] Stole, Lars A. and Jeffrey Zwiebel (1996b): "Organizational Design and Technology Choice under Intrafirm Bargaining”, American Economic Review, vol. 86, 195-222. 